ARTIGO

\title{
Impactos das cotas no ensino superior: um balanço do desempenho dos cotistas nas universidades estaduais
}

\author{
Daniel Calbino Pinheirol (D) \\ Rafael Diogo Pereira" (D) \\ Wescley Silva Xavier ${ }^{\prime \prime \prime}$ (D)
}

\begin{abstract}
RESUMO
O trabalho propôs sistematizar as pesquisas que avaliaram o desempenho dos beneficiários das ações afirmativas nas universidades estaduais. Por meio de uma revisão integrativa da literatura, buscou-se identificar a sua efetividade a partir de três dimensões: índices de rendimento acadêmico; taxa de evasão; e taxa de diplomação entre cotistas e ampla concorrência. Os resultados indicam que, ao longo dos dezessete anos de políticas afirmativas, os cotistas obtiveram rendimentos similares aos demais estudantes, superando-os, inclusive, nos índices de diplomação e nas menores taxas de evasão. Conclui-se que os dados derrubam o mito de que a qualidade da educação seria pior com as cotas, apesar da relevância do contínuo monitoramento destes resultados, uma vez que, ainda são escassos os enfoques na realidade das instituições estaduais.
\end{abstract}

\section{PALAVRAS-CHAVE}

ação afirmativa; universidades estaduais; avaliação de desempenho.

'Universidade Federal de São João Del-Rei, Sete Lagoas, MG, Brasil.

"Universidade Federal de Minas Gerais, Belo Horizonte, MG, Brasil.

"'Universidade Federal de Viçosa, Viçosa, MG, Brasil. 


\title{
THE IMPACTS OF QUOTA IN HIGHER EDUCATION: A BALANCE OF QUOTA STUDENTS IN THE STATE UNIVERSITIES
}

\begin{abstract}
The work proposed to systematize the researches that evaluated the performance of the beneficiaries of the affirmative actions in the state universities. Through an integrative literature review, we sought to identify its effectiveness from three dimensions: academic performance indexes; evasion rate; and rate of diploma between quota holders and wide competition. The results indicate that, over the seventeen years of quota policies in Brazil, the quota holders obtained similar income to the other students, even surpassing them in the indexes of graduation and in the lowest dropout rates. It is concluded that the data dispel the myth that the quality of education would be worse with the quotas, despite the relevance of the continuous monitoring of these results, since the focus on the reality of the state institutions is still scarce.
\end{abstract}

KEYWORDS

affirmative action; federal universities; performance evaluation.

\section{IMPACTOS DE LA CUOTAS EN LA EDUCACIÓN SUPERIOR: UN BALANCE DE LAS PERFORMANCES DE CUOTISTAS EN LAS UNIVERSIDADES ESTADUALES}

\section{RESUMEN}

El trabajo propuso sistematizar las investigaciones que evaluaron el desempeño de los beneficiarios de las acciones afirmativas en las universidades estatales. A través de una revisión integradora de la literatura, buscamos identificar su efectividad a partir de tres dimensiones: índices de rendimiento académico; tasa de evasión; y tasa de diploma entre titulares de cuotas y amplia competencia. Los resultados indican que, durante los diecisiete años de las políticas de cuotas en Brasil, los titulares de las cuotas obtuvieron ingresos similares a los otros estudiantes, incluso superándolos en los índices de graduación y en las tasas de abandono más bajas. Se concluye que los datos disipan el mito de que la calidad de la educación sería peor con las cuotas, a pesar de la relevancia del monitoreo continuo de estos resultados, ya que el enfoque en la realidad de las instituciones estatales aún es escaso.

PALABRAS CLAVE

acción afirmativa; universidades estaduales; evaluación de desempeño. 


\section{INTRODUÇÃO}

Em 2017, o coordenador de um curso de graduação da UFMG falou, durante uma cerimônia de formatura, que estava preocupado com a perda da qualidade da universidade. Ele exemplificou o problema dizendo: "eu jamais iria me consultar com um médico que tivesse ingressado no curso de medicina através de cotas”. (Takahashi, 2018, p. 1)

A epígrafe representa um dos mitos que perpassam as políticas de cotas desde a sua criação, em 2002. Na época, os argumentos contrários tomavam força nas narrativas de acadêmicos, como as de Maggie e Fry (2004) e Lewgoy (2005), que sustentavam a perda de qualidade da educação, uma vez que estudantes favorecidos por cotas, por serem aprovados com notas inferiores aos demais no exame de vestibular, reproduziriam menores coeficientes de rendimento acadêmico. Ademais, a dificuldade financeira para se sustentar durante o curso induziria os cotistas a abandonarem a educação superior (aumentando a evasão), ou, no mínimo, atrasando a conclusão do curso em comparação aos não cotistas (Wainer e Melguizo, 2018).

Cabe aqui estabelecer dois aspectos a respeito das expectativas supracitadas. Primeiro, em termos de transformação na sociedade, eliminam o caráter de mobilidade social inerente à política de cotas. Além disso, mesmo em termos pragmáticos, os argumentos se sustentavam em projeções futuras, predições de riscos, porém pouco ilustrando dados ou experiências para a corroboração argumentativa (Ferez Junior e Daflon, 2015), uma vez que, as políticas de cotas ainda se encontravam em fase inicial de implantação. No entanto, perpassados 17 anos desde as primeiras experiências nas universidades estaduais, observa-se que parte da discussão ainda se respalda nas mesmas previsões anteriores sem, contudo, recorrer a dados empíricos já disponíveis sobre a realidade brasileira, que evidenciam o caráter elitista ainda fortemente presente no acesso ao ensino superior.

O discurso referenciado pelo professor da Universidade Federal de Minas Gerais (UFMG), em 2017, não é um fato isolado. No final de 2019, uma matéria publicada no Jornal Gazeta do Povo, assinada por outro docente universitário, enfatizava que "as cotas são uma política ineficiente, irracional e insensata, que se movem por apelo emotivo, ao invés de argumentos racionais” (Ferraz, 2019, p. 1). O motivo: ao incluir nas universidades estudantes pautados por "aspectos que não sejam suas qualificações intelectuais, causamos dano ao indivíduo (que fracassará caso as disciplinas mantenham a exigência) e à própria instituição, que decairá inevitavelmente" (Ferraz, 2019, p. 1).

É válido frisar que, ao formularem suas argumentações, os pesquisadores não mencionaram publicações que divergem do suposto mito da perda da qualidade, e que ainda não há um balanço sistemático sobre o desempenho dos beneficiários (Ferez Junior e Daflon, 2015). Da mesma forma, são escassas as ferramentas consolidadas para o acompanhamento, em nível nacional, do sistema de reserva de vagas, do ingresso à conclusão. Não avaliar sistematicamente implica no risco de 
desqualificar a política ou atribuir aos beneficiários a responsabilidade por eventual fracasso em face de indicadores não conhecidos (Senkevics, 2018).

É nesse contexto que o presente artigo teve por objetivo mapear os estudos que analisaram o desempenho acadêmico dos estudantes após a implantação das políticas de cotas. Para tal, enquanto problema de pesquisa se questiona: como a literatura nacional aborda o desempenho entre os cotistas e estudantes da ampla concorrência, no que se refere ao coeficiente de rendimento (CR), índice de evasão escolar e taxa de diplomação nas universidades estaduais?

Enquanto recorte metodológico, optamos por analisar exclusivamente as instituições de educação superior da esfera estadual. A escolha ocorre por serem as pioneiras na implantação das cotas e, em tese, apresentarem maior potencial de resultados disponíveis sobre uma perspectiva longitudinal. Ressalta-se também a limitação de espaço para tratar em um mesmo artigo do universo de todas as instituições estaduais e universidades federais, com o devido detalhamento.

\section{BREVE HISTÓRICO DAS POLÍTICAS AFIRMATIVAS E O MITO DA QUALIDADE DA EDUCAÇÃO}

A Constituição Federal de 1988 e a Lei de Diretrizes e Bases da Educação de 1996 estabelecem que a educação deva respeitar o princípio da igualdade de condições para acesso e permanência na escola. Com efeito, dado o descompasso entre o ordenamento constitucional e sua efetividade para a educação, políticas de inclusão social foram formuladas, como as ações afirmativas, entendidas por iniciativas que visam promover a igualdade, reduzindo as injustiças sociais (Bayma, 2012).

O gradual processo de discussão e implantação das ações afirmativas faz parte de um contexto singular, o qual o Estado brasileiro fomentou iniciativas de igualdade racial, em resposta às demandas de movimentos sociais (Lemos, 2017). Um primeiro registro data de 1968, quando o Ministério do Trabalho se manifestou em favor da criação de uma lei que obrigasse empresas privadas a contratarem um percentual de empregados negros, mas tal lei não chegou a ser elaborada.

Foi somente nos anos de 1980, com a redemocratização do país, que se formulou o primeiro projeto, propondo uma ação compensatória em diversas áreas da vida social em reparação pelos séculos de discriminação. O debate, até então restrito ao movimento negro e de intelectuais, ampliou-se a partir dos anos 1990 para as demais esferas da sociedade (Moehlecke, 2002).

Em 1995, após a realização da Marcha Zumbi dos Palmares contra o Racismo envolvendo trinta mil ativistas em Brasília, o Governo lançou o Programa Nacional dos Direitos Humanos. São reconhecidos pela primeira vez os efeitos do racismo no País e a necessidade de políticas incluindo o desenvolvimento de ações afirmativas (Lemos, 2017). Seria necessário, contudo, mais oito anos para que o assunto entrasse efetivamente na agenda política, por meio do programa de combate ao racismo apresentado na Conferência Internacional contra o Racismo, Xenofobia e Intolerância, em Durban, na África do Sul, em 2001 (Moehlecke, 2002). 
Nesse contexto, o caso pioneiro e que ganhou grande repercussão foi a política de cotas que ocorreu no estado do Rio de Janeiro. As leis estaduais dos anos de 2001 e de 2002 previam até $45 \%$ reservas de vagas no ensino superior para egressos de escolas públicas, negros e pessoas com deficiência. Situação similar ocorreu no mesmo ano na Universidade Estadual de Mato Grosso do Sul, amparada por duas leis estaduais que estabeleceram a reserva de vagas para indígenas e negros.

Nos anos seguintes, respeitando as particularidades das legislações regionais, as instituições estaduais aderiram gradativamente às cotas. No final de 2019 , das 42 universidades estaduais, 38 adotaram algum tipo de modalidade de política de cotas, englobando diversas categorias de reservas de vagas, com destaque para: escola pública, negros, pardos e indígenas, quilombolas, deficientes, dependentes de militares, nativos do estado, professores da rede pública, ciganos e transgêneros.

Apesar dos avanços mencionados em quase duas décadas, o fenômeno ainda é marcado por debates, reproduzindo antigos mitos. Dentre eles, a crença na queda dos rendimentos acadêmicos, baixas diplomações e ampla evasão com a entrada de estudantes cotistas nas universidades (Maggie e Fry, 2004; Lewgoy, 2005; Wainer e Melguizo, 2018).

Como pano de fundo reverberam-se argumentos de que as políticas de cotas "autorizam indivíduos com habilidades controvertidas a cuidarem da saúde de outras pessoas" (Ferraz, 2019, p. 1).

$\mathrm{Na}$ contramão desses argumentos, a literatura nacional tem contribuído com estudos que avaliam os desempenhos dos estudantes após as políticas de cotas. Destaca-se a pesquisa de Cunha (2006), que investigou as primeiras turmas de cotistas da Universidade de Brasília, em especial no curso de medicina, registrando que os beneficiários obtiveram notas superiores aos demais colegas. Em um estudo mais recente na mesma instituição, Garcia e Jesus (2015) ampliaram o recorte, com ingressantes entre 2004 e 2014, constatando a mesma tendência.

Em uma perspectiva mais ampla, as pesquisas de Valente e Berry (2017), e Wainer e Melguizo (2018) analisaram o desempenho de todos os cursos das universidades federais no Exame Nacional de Desempenho dos Estudantes (ENADE) das edições 2009-2012 e 2012-2014, respectivamente. Os dois estudos comprovaram que não houve diferenças práticas entre os conhecimentos dos estudantes cotistas e de ampla concorrência, que inclusive, já se encontravam no final dos cursos de graduação.

Ressaltam-se ainda as investigações que apontaram para os menores índices de evasão dos cotistas em relação aos não cotistas, como as realizadas na Universidade de Brasília (Velloso, 2009), Universidade Federal de Santa Catarina (Leal da Silva, 2015), Universidade Federal de Viçosa (Moreira Silva, 2017) e na Universidade Federal do Espírito Santo (Arrigoni, 2018).

Apesar da relevância desses estudos em desmistificarem algumas crenças sobre as políticas de cotas no Brasil, consideramos relevante a sistematização dos trabalhos disponíveis na literatura, e em particular, no contexto das universidades estaduais. Isto pode facilitar uma visão panorâmica sobre o tema, além de contribuir para uma avaliação mais precisa sobre a efetividade das políticas de cotas ao longo desses 17 anos. 


\section{PERCURSO METODOLÓGICO}

Para responder ao objetivo geral deste artigo, recorreu-se a uma pesquisa bibliográfica na literatura nacional entre os meses de agosto a dezembro de 2019. Foram analisadas 69 dissertações e teses disponíveis no banco da Capes e na Biblioteca Digital Brasileira que tratavam do tema, bem como 24 artigos disponíveis em cada um dos periódicos online do Extrato A1, A2 e B1 (quadriênio 2013-2016) das áreas de Educação, Administração e Sociologia.

O método adotado foi a pesquisa bibliométrica (Caldas e Tinoco, 2004), viabilizando o mapeamento da produção acerca do tema erigido, como também representando uma ferramenta primária para a análise do comportamento dos pesquisadores em suas decisões na construção desse corpus de conhecimento.

Em virtude do baixo número de trabalhos encontrados (apenas cinco dissertações, duas teses e dois artigos em periódicos), optou-se por ampliar a investigação a partir da consulta na plataforma scielo.br e no buscador Google Acadêmico, expandindo a amostra para os periódicos das demais áreas do saber e com extratos inferiores na Capes (B2 a C), incluindo também livros disponíveis no formato online que tratassem da temática.

O intervalo empírico das publicações ocorreu entre 2002 (início das políticas de cotas), até o mês de dezembro de 2019. A busca pelos trabalhos valeu-se do uso de palavras-chave que orientassem o filtro dos buscadores online. Utilizou-se, assim, os termos "cotas", "políticas afirmativas", "ação afirmativa" e "política de cotas", que estivessem presentes no título, resumo, palavras-chave, assunto e/ou corpo dos textos. Em seguida, realizou-se uma segunda revisão a partir de uma busca avançada nas plataformas, adicionando o nome de cada uma das universidades estaduais que aderiram às cotas, juntamente com as etimologias citadas. $\mathrm{O}$ intuito era revisar se algum trabalho passou despercebido ou não foi filtrado pela primeira busca.

Após a coleta dos trabalhos, foi realizada a leitura sistemática do conteúdo, selecionando aqueles que trataram de pelo menos uma das dimensões do desempenho acadêmico (rendimento, diplomação e/ou evasão). Nesse momento, foram excluídas as investigações que se limitaram a fornecer dados isolados, sem estabelecer comparativos dos cotistas com o universo dos demais estudantes (Figura 1).

Deste modo, foram encontrados 15 trabalhos que exploraram a realidade de 12 universidades estaduais. O Quadro 1 sintetiza as pesquisas encontradas, situando-as a partir das legislações que regem as cotas em cada instituição.

Para a análise dos dados, foram adotadas três categorias (rendimento acadêmico, taxas de evasão e índices de diplomação), comparando o desempenho dos estudantes da instituição, de acordo com o curso, área do saber e/ou campus investigado, disponível nos dados dos trabalhos.

Em virtude das particularidades da legislação de cada estado e da ampla modalidade de cotas, dividimos a análise, para fins comparativos, entre os estudantes ingressantes da ampla concorrência, cotistas de escolas públicas e/ou cotistas raciais (preto, pardo, indígena), uma vez que a literatura encontrada não apresentou dados sobre as outras modalidades de cotas na realidade das universidades estaduais. 


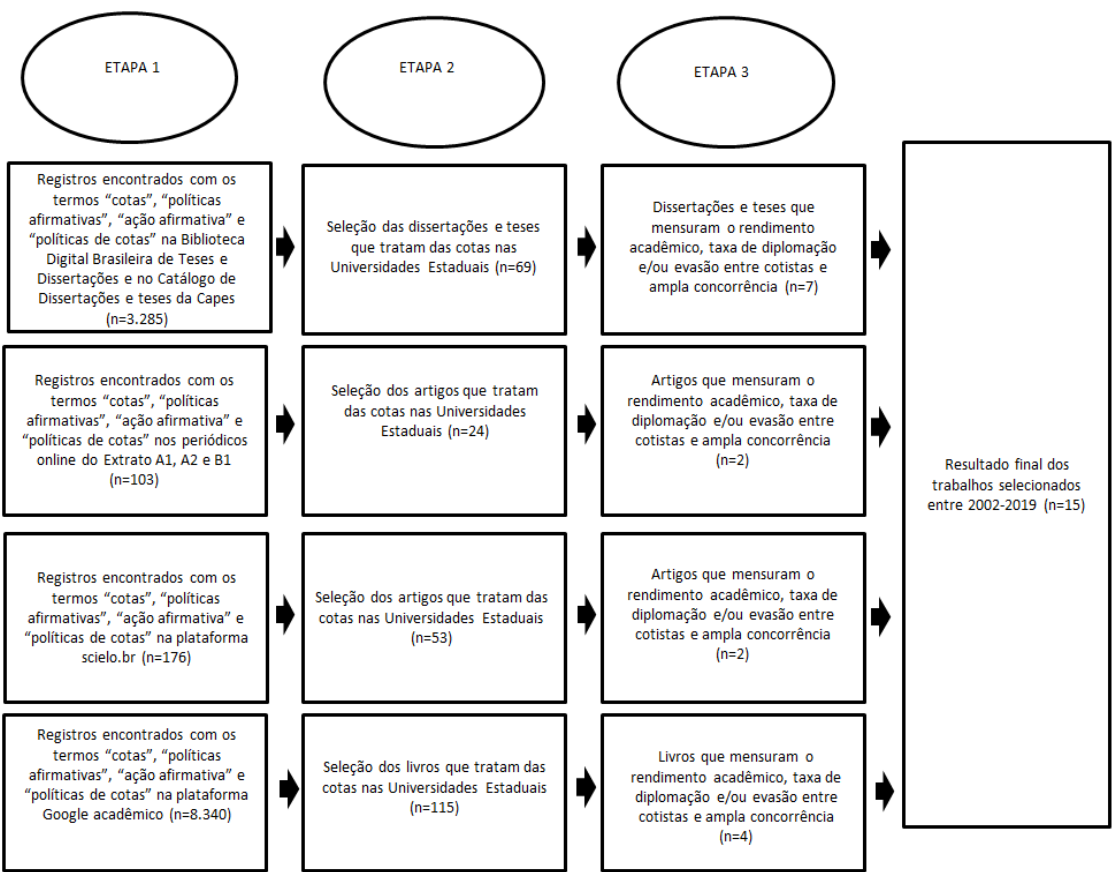

Figura 1 - Percurso metodológico utilizado.

\section{AVALIAÇÃO DO DESEMPENHO DOS COTISTAS NO BRASIL}

\section{PESQUISAS DAS UNIVERSIDADES ESTADUAIS NA REGIÃO SUDESTE}

A Região Sudeste possui nove Universidades Estaduais, sendo quatro no estado de São Paulo, três no Rio de Janeiro e duas em Minas Gerais. Um primeiro aspecto a ser ressaltado diz respeito ao baixo número de trabalhos que analisaram as universidades da Região Sudeste. Registrou-se seis pesquisas que contemplaram apenas três instituições estaduais (UERJ, UENF e UNIMONTES). Chama a atenção o fato de as universidades do estado de São Paulo não terem sido objeto de investigação, não obstante a importância das mesmas no Brasil. Uma hipótese pode ser a adesão tardia, uma vez que a Universidade de São Paulo (USP) e a Universidade Estadual de Campinas (Unicamp) só aderiram ao sistema de cotas nos vestibulares de 2018 e 2019, respectivamente.

Referente às publicações, a maioria (quatro) investigou a UERJ, possivelmente pelo seu pioneirismo. A primeira é a de Bezerra e Gurgel (2011), que analisaram o desempenho acadêmico e a evasão entre os estudantes da ampla concorrência e a soma de todas as modalidades de cotas. Em termos metodológicos, estabeleceram como recorte as turmas de ingressantes nos vestibulares de 2005 e 2006, de seis 
Quadro 1 - Balanço dos trabalhos na literatura.

\begin{tabular}{|c|c|c|c|}
\hline Região & Universidade & Política de Cotas & Autores \\
\hline Sudeste & $\begin{array}{c}\text { UERJ } \\
\text { (Universidade } \\
\text { Estadual do Rio } \\
\text { de Janeiro) }\end{array}$ & $\begin{array}{l}\text { Início no vestibular de } 2003 \text {, reservando } 20 \% \text { das } \\
\text { vagas para estudantes de escolas públicas, } 20 \% \\
\text { para negros e } 5 \% \text { para deficientes físicos e minorias } \\
\text { étnicas. Entretanto, após revogações e alterações, a } \\
\text { lei vigente estabelece } 20 \% \text { para negros e indígenas; } \\
20 \% \text { para os estudantes da rede pública; } 5 \% \text { para } \\
\text { pessoas com deficiências e filhos de policiais civis, } \\
\text { militares, inspetores de segurança ou administração } \\
\text { penitenciária, mortos ou incapacitados por razão } \\
\text { de serviço. }\end{array}$ & $\begin{array}{l}\text { Bezerra } \\
\text { e Gurgel } \\
\text { (2011); } \\
\text { Cicalò } \\
\text { (2008); } \\
\text { Mendes } \\
\text { Junior } \\
\text { (2014); } \\
\text { Machado } \\
\text { (2013) }\end{array}$ \\
\hline Sudeste & $\begin{array}{l}\text { UENF } \\
\text { (Universidade } \\
\text { Estadual do Norte } \\
\text { Fluminense Darcy } \\
\text { Ribeiro) }\end{array}$ & 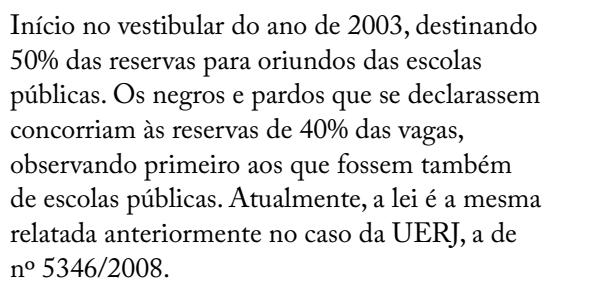 & $\begin{array}{l}\text { Brandão } \\
\text { e Matta } \\
(2007)\end{array}$ \\
\hline Sudeste & $\begin{array}{l}\text { UNIMONTES } \\
\text { (Universidade } \\
\text { Estadual de } \\
\text { Montes Claros) }\end{array}$ & $\begin{array}{l}\text { A instituição aderiu às reservas no vestibular de } \\
2005 \text {, destinando } 45 \% \text { das vagas. A partir da Lei } \\
\text { Estadual n } 22.570 / 2017 \text {, os percentuais saltaram } \\
\text { para } 50 \% \text { de reserva, divididas em: I negros, de } \\
\text { baixa renda da escola pública (24\%); II. Indígenas, } \\
\text { de baixa renda da escola pública (5\%); candidatos } \\
\text { de baixa renda egressos de escola pública (16\%); IV. } \\
\text { Pessoas com deficiência (5\%). }\end{array}$ & $\begin{array}{l}\text { Barros } \\
(2010)\end{array}$ \\
\hline Sul & $\begin{array}{c}\text { UNIOESTE } \\
\text { (Universidade } \\
\text { Estadual do Oeste } \\
\text { do Paraná) }\end{array}$ & $\begin{array}{l}\text { A instituição aderiu às cotas no vestibular de } 2009 \text {, } \\
\text { estabelecendo } 40 \% \text { das vagas para estudantes de } \\
\text { escolas públicas. A partir de } 2014 \text { adotou 50\% das } \\
\text { vagas ao Sistema de Seleção Unificada, ampliando } \\
\text { a reserva de vagas de } 40 \text { para } 50 \% \text { de escolas } \\
\text { públicas. }\end{array}$ & $\begin{array}{l}\text { Corbari } \\
(2018)\end{array}$ \\
\hline Sul & $\begin{array}{l}\text { UEL } \\
\text { (Universidade } \\
\text { Estadual de } \\
\text { Londrina) }\end{array}$ & $\begin{array}{l}\text { A instituição iniciou as cotas no vestibular de } \\
2005 \text {, destinando } 40 \% \text { das vagas para oriundos } \\
\text { de escolas públicas, sendo até metade dessas } \\
\text { vagas aos que se declarassem negros. A partir da } \\
\text { resolução } 015 / 2012 \text {, as reservas se mantiveram } \\
\text { em } 40 \% \text {, porém, garantindo metade aos negros, } \\
\text { independentemente do número de inscritos. }\end{array}$ & $\begin{array}{l}\text { Gabriel } \\
\text { (2013); Silva } \\
\text { e Pacheco } \\
\text { (2013) }\end{array}$ \\
\hline Sul & $\begin{array}{c}\text { UEPG } \\
\text { (Universidade } \\
\text { Estadual de Ponta } \\
\text { Grossa) }\end{array}$ & $\begin{array}{l}\text { A instituição aderiu às cotas no vestibular de } 2007 \text {, } \\
\text { estabelecendo a reserva de } 10 \% \text { das vagas para } \\
\text { estudantes de escolas públicas e } 5 \% \text { de escolas } \\
\text { públicas que se declarassem negros. E, a cada ano, } \\
\text { durante um período de } 8 \text { anos, o número de vagas } \\
\text { foi acrescido de } 5 \% \text { para estudantes de escolas } \\
\text { públicas e } 1 \% \text { para estudantes negros. }\end{array}$ & $\begin{array}{l}\text { Souza } \\
(2012)\end{array}$ \\
\hline
\end{tabular}


Quadro 1 - Continuação.

\begin{tabular}{|c|c|c|c|}
\hline Região & Universidade & Política de Cotas & Autores \\
\hline $\begin{array}{l}\text { Centro- } \\
\text { Oeste }\end{array}$ & $\begin{array}{c}\text { UEMS } \\
\text { (Universidade } \\
\text { Estadual de Mato } \\
\text { Grosso do Sul) }\end{array}$ & $\begin{array}{l}\text { A universidade aderiu às cotas no vestibular de } \\
2003 \text {, que dispôs da reserva de vagas de } 10 \% \text { para } \\
\text { indígenas e } 20 \% \text { para negros. A partir da resolução } \\
\text { de } 31 \text { de outubro de } 2018 \text {, aprovaram para os } \\
\text { cursos de pós-graduação acrescer } 5 \% \text { de vagas } \\
\text { extras para deficientes, quilombolas, travestis e } \\
\text { transexuais. }\end{array}$ & $\begin{array}{l}\text { Benatti } \\
\text { (2017); } \\
\text { Cordeiro } \\
(2008)\end{array}$ \\
\hline $\begin{array}{l}\text { Centro- } \\
\text { Oeste }\end{array}$ & $\begin{array}{c}\text { UNEMAT } \\
\text { (Universidade do } \\
\text { Estado do Mato } \\
\text { Grosso) }\end{array}$ & $\begin{array}{l}\text { A instituição aderiu às políticas de cotas em } \\
14 \text { de dezembro de } 2004 \text {, entrando em vigor a } \\
\text { partir do vestibular de } 2005 / 2 \text {. As vagas foram } \\
\text { disponibilizadas em } 25 \% \text { para cotistas negros em } \\
\text { todos os cursos de graduação. }\end{array}$ & Costa (2015) \\
\hline Nordeste & $\begin{array}{c}\text { UNEB } \\
\text { (Universidade do } \\
\text { Estado da Bahia) }\end{array}$ & $\begin{array}{l}\text { A instituição aderiu às cotas no vestibular de } 2003 \text {, } \\
\text { destinando } 40 \% \text { das vagas para negros de escolas } \\
\text { públicas do Estado da Bahia. A partir da resolução } \\
\text { no } 1339 \text { de } 2018 \text {, ampliou } 5 \% \text { de vagas extras para } \\
\text { indígenas; quilombolas; ciganos; pessoas com } \\
\text { deficiência, transtorno do espectro autista e altas } \\
\text { habilidades; transexuais, travestis e transgêneros. }\end{array}$ & $\begin{array}{l}\text { Santos } \\
\text { (2007); } \\
\text { Mattos, } \\
\text { Macedo } \\
\text { e Mattos } \\
\text { (2013) }\end{array}$ \\
\hline
\end{tabular}

cursos de graduação. Ao lançarem mão de dados fornecidos pelo sistema interno da instituição, utilizaram da estatística descritiva para correlacionar a média acadêmica acumulada entre 2005 e 2009.

Os resultados apontaram que, ao longo de quatro anos, a média das notas dos cotistas (7,7 - turmas de 2005 e 7,9 - turmas de 2006) se aproximou da dos estudantes de ampla concorrência (8 - turmas de 2005 e 8,2 - turmas de 2006). As diferenças nas médias foram de 0,3 pontos no acumulado, o que para os autores é considerado insignificante em termos de comparação (Quadro 2).

Quanto à evasão, identificaram que entre os cotistas o percentual se mostrou praticamente a metade $(12,2 \%$ — turmas de 2005 e $9,3 \%$ — turmas de 2006) daqueles observados entre os sem cotas $(23,2 \%$ - turmas de 2005 e $22,6 \%$ - turmas de 2006). Foram destaques os cursos de Administração e Pedagogia RJ, turmas de 2006, cujas diferenças situaram-se próximas de três vezes em relação à ampla concorrência (Quadro 2).

A segunda investigação sobre a UERJ, de Cicalò (2008), também pesquisou o desempenho acadêmico e a taxa de evasão. No entanto, optou por um universo mais amplo de cursos, lançando mão de 49 modalidades de graduação entre o período de 2003-2007, além de detalhar o tipo de cota em oriundos de escolas públicas e negros.

No que se refere ao desempenho acadêmico, os resultados indicam que as diferenças entre os cotistas negros $(6,37)$ e estudantes da ampla concorrência $(6,41)$ foram inexpressivas (diferença de 0,04 pontos). No entanto, o dado surpreendente para o autor foram os cotistas de escolas públicas $(6,56)$, que apresentaram rendimentos, inclusive, superiores aos não cotistas (Quadro 3). 
Quadro 2-Desempenho Acadêmico e evasão em seis cursos da Universidade do Estado do Rio de Janeiro.

\begin{tabular}{|l|c|c|c|c|c|c|c|c|}
\hline \multirow{2}{*}{ Curso } & \multicolumn{2}{|c|}{$\begin{array}{c}\text { Coeficiente } \\
\text { de rendimento } \\
\text { em 2005 }\end{array}$} & \multicolumn{2}{|c|}{$\begin{array}{c}\text { Coeficiente } \\
\text { de rendimento } \\
\text { em 2006 }\end{array}$} & \multicolumn{2}{|c|}{$\begin{array}{c}\text { Evasão: } \\
\text { ingressantes } \\
\text { de 2005 (\%) }\end{array}$} & \multicolumn{2}{|c|}{$\begin{array}{c}\text { Evasão: } \\
\text { ingressantes } \\
\text { de 2006 (\%) }\end{array}$} \\
\cline { 2 - 10 } & Cotistas & $\begin{array}{c}\text { Sem } \\
\text { cotas }\end{array}$ & Cotistas & $\begin{array}{c}\text { Sem } \\
\text { cotas }\end{array}$ & Cotistas & $\begin{array}{c}\text { Sem } \\
\text { cotas }\end{array}$ & Cotistas & $\begin{array}{c}\text { Sem } \\
\text { cotas }\end{array}$ \\
\hline Administração & 8 & 8 & 7,9 & 8 & 14,8 & 28,8 & 9,2 & 29,2 \\
\hline Direito & 7,7 & 8,5 & 7,7 & 8,8 & 6,2 & 7,1 & 6,2 & 8,9 \\
\hline $\begin{array}{l}\text { Engenharia } \\
\text { Química }\end{array}$ & 6,6 & 7,1 & 6,7 & 7,4 & 27,7 & 38,6 & 18,0 & 30,1 \\
\hline Medicina & 7,4 & 7,6 & 7,7 & 7,7 & 4,6 & 5,8 & 4,6 & 3,9 \\
\hline Pedagogia RJ & 8,4 & 8,6 & 8,9 & 8,9 & 4,2 & 33,1 & 6,4 & 22,6 \\
\hline $\begin{array}{l}\text { Pedagogia } \\
\text { Interior }\end{array}$ & 8,4 & 8,3 & 8,5 & 8,7 & 15,7 & 26 & 11,7 & 27,2 \\
\hline Média Total & $\mathbf{7 , 7}$ & $\mathbf{8}$ & $\mathbf{7 , 9}$ & $\mathbf{8 , 2}$ & $\mathbf{1 2 , 2}$ & $\mathbf{2 3 , 2}$ & $\mathbf{9 , 3}$ & $\mathbf{2 0 , 3}$ \\
\hline
\end{tabular}

Fonte: adaptado de Bezerra e Gurgel (2011).

Quanto às taxas de evasão acumulada entre 2003 a 2007, registrou-se que os maiores percentuais ocorreram nos estudantes da ampla concorrência (17\%), enquanto os números caíram para $13 \%$ nos estudantes cotistas negros e $10 \%$ para os cotistas de escolas públicas (Quadro 3).

Quadro 3 - Desempenho acadêmico e evasão em 49 cursos da Universidade do Estado do Rio de Janeiro.

\begin{tabular}{|l|c|c|c|c|c|c|}
\hline \multirow{2}{*}{ Cursos } & \multicolumn{3}{|c|}{$\begin{array}{c}\text { Coeficiente de rendimento } \\
\text { entre 2003-2007 }\end{array}$} & \multicolumn{3}{|c|}{$\begin{array}{c}\text { Taxas de evasão (\%) } \\
\text { entre 2003-2007 }\end{array}$} \\
\cline { 2 - 7 } & $\begin{array}{c}\text { Cotistas da } \\
\text { rede pública }\end{array}$ & $\begin{array}{c}\text { Cotistas } \\
\text { negros }\end{array}$ & $\begin{array}{c}\text { Sem } \\
\text { Cotas }\end{array}$ & $\begin{array}{c}\text { Cotistas } \\
\text { da rede } \\
\text { pública }\end{array}$ & $\begin{array}{c}\text { Cotistas } \\
\text { negros }\end{array}$ & $\begin{array}{c}\text { Sem } \\
\text { Cotas }\end{array}$ \\
\hline História & 7,15 & 7,22 & 5,67 & 4,1 & 5,38 & 19,2 \\
\hline Direito & 7,10 & 7,08 & 7,94 & 5,35 & 3,64 & 4,83 \\
\hline Engenharia & 4,7 & 4,11 & 4,29 & - & - & - \\
\hline Média de 49 cursos & $\mathbf{6 , 5 6}$ & $\mathbf{6 , 3 7}$ & $\mathbf{6 , 4 1}$ & $\mathbf{1 0}$ & $\mathbf{1 3}$ & $\mathbf{1 7}$ \\
\hline
\end{tabular}

Fonte: adaptado de Cicalò (2008) ${ }^{1}$.

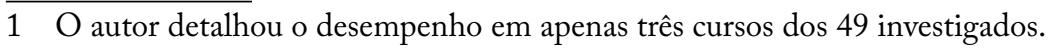


O terceiro estudo referente à UERJ, de Mendes Junior (2014), além de analisar os rendimentos acadêmicos e as taxas de evasão, incluiu os índices de diplomação dos estudantes. Enquanto recorte metodológico, utilizou-se de 43 turmas ingressantes do vestibular de 2005 que se graduaram entre os anos de 2009-2011, dividindo-os entre ampla concorrência e todas as modalidades de cotistas.

Para coleta de dados, recorreu-se à ferramenta desenvolvida na própria instituição, Business Intelligence, que extrai informações detalhadas das bases de dados da graduação e as consolida em estatística descritiva. Diferentemente da metodologia dos estudos anteriores, o autor optou por criar uma variável chamada de "dificuldade relativa do curso" que, a partir do coeficiente de rendimento médio dos alunos de cada carreira, foi dividida em três grupos: baixa, média e alta dificuldade relativa.

Enquanto resultados, os diferenciais de rendimento entre os grupos de não cotistas e cotistas reproduziu uma diferença média absoluta para todas as carreiras de 0,4 pontos em 2006 e 2009, a favor da ampla concorrência. No entanto, ao estratificar por níveis de dificuldade, observou-se que a diferença em termos de notas médias aumentou conforme a dificuldade relativa do curso. Em cursos considerados de alta dificuldade, o diferencial chegou a 0,12 e naqueles definidos como baixa dificuldade, o hiato diminuiu para 0,6 no primeiro ano, 2006 (Quadro 4). Assim, para o autor, houve um diferencial significativo em termos de notas médias para os grupos não cotistas e cotistas, as quais foram expressivas em cursos que exigem maior dedicação e conhecimento prévio dos alunos.

Quadro 4-Desempenho Acadêmico, Diplomação e evasão em 43 cursos da Universidade do Estado do Rio de Janeiro.

\begin{tabular}{|l|c|c|c|c|c|c|c|c|c|c|}
\hline & \multicolumn{2}{|c|}{$\begin{array}{c}\text { Coeficiente } \\
\text { de } \\
\text { rendimento } \\
\text { em 2006 }\end{array}$} & \multicolumn{2}{c|}{$\begin{array}{c}\text { Coeficiente } \\
\text { de } \\
\text { rendimento } \\
\text { em 2009 }\end{array}$} & \multicolumn{2}{|c|}{$\begin{array}{c}\text { Diplomação } \\
\text { até 0 ano } \\
\text { de 2011 (\%) }\end{array}$} & \multicolumn{2}{|c|}{$\begin{array}{c}\text { Evasão em } \\
\text { 2005 (\%) }\end{array}$} & \multicolumn{2}{|c|}{$\begin{array}{c}\text { Evasão } \\
\text { entre } \\
\mathbf{2 0 0 6 - 2 0 0 9} \\
(\%)\end{array}$} \\
\cline { 2 - 13 } & Cotas & $\begin{array}{c}\text { Sem } \\
\text { cotas }\end{array}$ & Cotas & $\begin{array}{c}\text { Sem } \\
\text { cotas }\end{array}$ & Cotas & $\begin{array}{c}\text { Sem } \\
\text { cotas }\end{array}$ & Cotas & $\begin{array}{c}\text { Sem } \\
\text { cotas }\end{array}$ & Cotas & $\begin{array}{c}\text { Sem } \\
\text { cotas }\end{array}$ \\
\hline $\begin{array}{l}\text { Dificuldade } \\
\text { baixa }\end{array}$ & 7,4 & 7,9 & 7,1 & 7,8 & 61,4 & 53,8 & 3,8 & 12,8 & 32,6 & 44,9 \\
\hline $\begin{array}{l}\text { Dificuldade } \\
\text { média }\end{array}$ & 7,1 & 7,4 & 6,7 & 7,2 & 49,0 & 42 & 7,2 & 15,4 & 39,8 & 47,1 \\
\hline $\begin{array}{l}\text { Dificuldade } \\
\text { alta }\end{array}$ & 4,6 & 5,2 & 4,8 & 5,3 & 28,7 & 29,7 & 7,2 & 18 & 26,4 & 30,7 \\
\hline $\begin{array}{l}\text { Média total } \\
\text { de 43 cursos }\end{array}$ & $\mathbf{6 , 8}$ & $\mathbf{7 , 2}$ & $\mathbf{6 , 7}$ & $\mathbf{7 , 1}$ & $\mathbf{4 6 , 7}$ & $\mathbf{4 2 , 1}$ & $\mathbf{5 , 8}$ & $\mathbf{1 5 , 6}$ & $\mathbf{3 2 , 8}$ & $\mathbf{3 9 , 3}$ \\
\hline
\end{tabular}

Fonte: adaptado de Mendes Junior (2014).

No entanto, se as diferenças foram maiores na média do coeficiente de rendimento, nos índices de diplomação foram os cotistas que obtiveram as maiores médias (46,7\%) em comparação com a ampla concorrência (32,8\%), em 43 turmas analisadas 
(Quadro 4). Ainda que os dados não permitam realizar maiores inferências, uma vez que não tivemos acesso ao desvio padrão das médias, é relevante sublinhar que o desempenho acadêmico a partir das taxas de diplomação serve como um indicador comparativo que amplia a análise para além da soma total dos coeficientes de rendimentos.

Quanto à evasão, os dados encontrados reproduziram a mesma tendência dos trabalhos anteriores, sendo menor entre cotistas $(32,8 \%)$ em comparação com a ampla concorrência $(39,2 \%)$ (Quadro 4).

O último estudo sobre a UERJ, de Machado (2013), realizou um censo sobre os índices de diplomação e evasão em todos os estudantes da instituição matriculados entre o período de 2003-2012. Ao recorrer às informações disponíveis no relatório do levantamento de cotas da instituição de 2012, o autor dividiu os grupos entre ampla concorrência e todas as modalidades de cotas.

Os resultados indicaram que enquanto $26 \%$ da ampla concorrência graduou-se no período analisado, esse número subiu para $33 \%$ entre os beneficiários da política de cotas. Em sentido oposto, observou-se menores índices de evasão entre os cotistas (23\%) em comparação com a ampla concorrência (36\%) (Quadro 5).

Quadro 5 - Evasão e diplomação nas matrículas de 2003 a 2012 da Universidade do Estado do Rio de Janeiro.

\begin{tabular}{|l|c|c|c|c|}
\hline \multirow{2}{*}{ Curso } & \multicolumn{2}{|c|}{$\begin{array}{c}\text { Índice de diplomação } \\
(\%) \text { entre 2003-2012 }\end{array}$} & \multicolumn{2}{c|}{$\begin{array}{c}\text { Taxas de evasão } \\
(\%) \text { entre 2003-2012 }\end{array}$} \\
\cline { 2 - 5 } & Cotistas & Sem cotas & Cotistas & Sem cotas \\
\hline Todas as matrículas da instituição & 33 & 26 & 23 & 36 \\
\hline
\end{tabular}

Fonte: adaptado de Machado (2013).

Feitas as considerações sobre a realidade da UERJ, é possível notar que as quatro pesquisas confluíram para resultados semelhantes ao identificar menor evasão entre os cotistas (Bezerra e Gurgel, 2011; Cicalò, 2008; Mendes Junior, 2014; Machado, 2013), bem como os maiores índices de diplomação dos beneficiários das cotas (Mendes Junior, 2014; Machado, 2013), desmistificando na realidade da UERJ a crença nos maiores abandonos e quedas na diplomação após a adesão às cotas.

Quanto ao rendimento acadêmico, distintos recortes metodológicos, possivelmente, implicaram em diferentes percentuais. Enquanto, Bezerra e Gurgel (2011) partiram de uma amostra menor, composta de dois processos seletivos, Cicalò (2008) ampliou o universo para 49 cursos entre 2003 e 2007, e por fim, o trabalho de Mendes Junior (2014), com a estratificação em três níveis de dificuldade. Esses percursos indicaram perspectivas diferentes sobre o rendimento dos estudantes, seja a favor dos cotistas (Cicalò, 2008), sem diferenças significativas entre os grupos (Bezerra e Gurgel, 2011), seja a favor da ampla concorrência, quando analisado pelo grau de dificuldade dos cursos (Mendes Junior, 2014).

Conforme sublinha Sacristan (1995), o processo de avaliação é uma construção social, as informações tidas como objetivas passam por escolha, seleção, organização, e portanto, interpretação. Assim, não é possível pensar que haja uma única resposta para cada aspiração. A complexidade do processo avaliativo se torna 
reflexo do fenômeno social em que toda avaliação pública está inserida. Apesar dessa singularidade, em vista dos resultados na UERJ, é possível inferir que os cotistas foram capazes de acompanhar o desenvolvimento dos cursos satisfatoriamente, o que permite apreciar as cotas como um instrumento de inclusão, mais do que um recurso destinado a facilitar o acesso à educação formal (Bezerra e Gurgel, 2011).

Outra estadual do Rio de Janeiro investigada pela literatura foi a UENF, realizada por Brandão e Matta (2007). Os autores trataram do rendimento acadêmico e taxa de evasão de 415 estudantes oriundos de 13 cursos da primeira geração de cotistas, do vestibular de 2003. Por meio de dados fornecidos pela Secretaria Acadêmica da instituição, os autores lançaram mão do coeficiente de rendimento acumulado nos dois primeiros períodos de cada curso, dividindo os cotistas em negros e rede pública.

Enquanto resultados, as médias entre os grupos de cotistas da rede pública $(6,9)$ e ampla concorrência (7) não apresentaram diferenças significativas. Contudo, os cotistas negros $(6,6)$ registraram os menores índices na média comparada. Em contrapartida, no que se refere às taxas de evasão ocorreu uma inversão proporcional: os cotistas negros apresentaram os menores índices de evasão (13,9\%) em comparação com a ampla concorrência $(17,5 \%)$ e, diferente do encontrado na UERJ, os cotistas da rede pública lideraram os percentuais de evasão (24,9\%) (Quadro 6).

Quadro 6-Desempenho Acadêmico e evasão em treze cursos da Universidade Estadual do Norte Fluminense.

\begin{tabular}{|l|c|c|c|c|c|c|}
\hline \multirow{2}{*}{ Curso } & \multicolumn{3}{|c|}{$\begin{array}{c}\text { Coeficiente de } \\
\text { rendimento em dois } \\
\text { semestres de 2003 }\end{array}$} & \multicolumn{3}{c|}{$\begin{array}{c}\text { Evasão (\%) } \\
2003-2005\end{array}$} \\
\cline { 2 - 7 } & $\begin{array}{c}\text { Cotistas } \\
\text { negros }\end{array}$ & $\begin{array}{c}\text { Cotistas da } \\
\text { rede pública }\end{array}$ & $\begin{array}{c}\text { Sem } \\
\text { cotas }\end{array}$ & $\begin{array}{c}\text { Cotistas } \\
\text { negros }\end{array}$ & $\begin{array}{c}\text { Cotistas da } \\
\text { rede pública }\end{array}$ & Sem cotas \\
\hline Engenharia de Petróleo & 6,8 & 7,7 & 8,6 & 0 & 0 & 14 \\
\hline Medicina Veterinária & 5,8 & 5,3 & 5,6 & 0 & 22,2 & 19,3 \\
\hline Biologia Bacharelado & 5,8 & 6,8 & 6,6 & 15,7 & 10 & 23,9 \\
\hline Licenciatura Biologia & 7 & 6,7 & 7,5 & 40 & 8,3 & 20 \\
\hline Ciências Sociais & 7,3 & 7,5 & 8 & 14,2 & 50 & 0 \\
\hline Engenharia Metalúrgica & 6,6 & 4,9 & 7,3 & 11 & 0 & 25 \\
\hline Engenharia Civil & 5,6 & 6,3 & 5,6 & 0 & 0 & 13 \\
\hline Física & 7,9 & 7,9 & 7 & 0 & 50 & 33,3 \\
\hline Matemática & 7,1 & 7 & 8 & 0 & 0 & 0 \\
\hline Agronomia & 5,7 & 7,1 & 6,3 & 20 & 0 & 19,2 \\
\hline Química & - & 7 & 7,6 & - & 33,3 & 16,3 \\
\hline Zootecnia & 6,2 & 6,3 & 6,1 & 33,3 & 100 & 26,3 \\
\hline Educação & 7,4 & 7,9 & 7,2 & 33,3 & 50 & 18,1 \\
\hline Total das médias & $\mathbf{6 , 6}$ & $\mathbf{6 , 9}$ & $\mathbf{7}$ & $\mathbf{1 3 , 9}$ & $\mathbf{2 4 , 9}$ & $\mathbf{1 7 , 5}$ \\
\hline
\end{tabular}

Fonte: adaptado de Brandão e Matta (2007). 
Uma hipótese para explicar esses resultados, segundo Brandão e Matta (2007), é que os cotistas matriculados na UERJ tendem a atribuir alto valor ao curso em que ingressam. Por isto, persistem em maior proporção na universidade a despeito de menores coeficientes de rendimento médio.

Apesar de não termos encontrado outros estudos que pudessem complementar as análises de Brandão e Matta (2007) com dados mais atualizados sobre a UENF, os dados trazidos pelos autores, em relação à primeira geração de cotistas da instituição, põem em xeque o argumento contrário às cotas pautado em um possível aumento da evasão de estudantes cotistas.

Por fim, em Minas Gerais registrou-se o estudo de caso de Barros (2010), que analisou o rendimento acadêmico dos estudantes do curso de medicina da UNIMONTES. O autor fez uma análise longitudinal dos ingressantes nos dois primeiros vestibulares do ano de 2005 , comparando a evolução das notas durante seis semestres do curso. A avaliação do rendimento acadêmico foi gerada a partir da consulta nas cadernetas escolares (diários) das turmas, dividindo entre ampla concorrência e todas as modalidades de cotas.

Enquanto resultados, constatou-se que durante a graduação, não se registrou dificuldades de progressão dos cotistas. Observou-se que as diferenças das médias de desempenho diminuíram entre os dois grupos durante a graduação, sendo que na turma dos ingressantes de 2005/2, os cotistas superaram os estudantes de ampla concorrência na média acumulada até o sexto período (Quadro 7).

Quadro 7-Desempenho acadêmico em seis semestres do curso de medicina da Universidade Estadual de Montes Claros.

\begin{tabular}{|l|c|c|c|c|}
\hline \multirow{2}{*}{$\begin{array}{l}\text { Murso } \\
\text { Medicina }\end{array}$} & \multicolumn{2}{|c|}{$\begin{array}{c}\text { Coeficiente de rendimento da } \\
\text { Turma 2015.1 }\end{array}$} & $\begin{array}{r}\text { Coeficiente de rendimento da } \\
\text { Turma 2015.2 }\end{array}$ \\
\cline { 2 - 5 } & Cotistas & Sem cotas & Cotistas & Sem cotas \\
\hline Primeiro semestre & 83,1 & 84,6 & 88,3 & 87,8 \\
\hline Segundo semestre & 72,8 & 76,3 & 81,5 & 83 \\
\hline Terceiro semestre & 80 & 84,4 & 83,8 & 80,7 \\
\hline Quarto semestre & 81,6 & 84,8 & 78 & 72,9 \\
\hline Quinto semestre & 79,7 & 82,6 & 83 & 80,1 \\
\hline Sexto semestre & 73 & 77 & 83,6 & 80,5 \\
\hline Média Geral & $\mathbf{7 8 , 3}$ & $\mathbf{8 1 , 6}$ & $\mathbf{8 3}$ & $\mathbf{8 0 , 8}$ \\
\hline
\end{tabular}

Fonte: adaptado de Barros (2010).

Apesar da pequena amostra e da análise focada unicamente nas primeiras turmas de cotistas da instituição, os achados se mostram relevantes ao situar o satisfatório rendimento dos beneficiários em uma das áreas mais concorridas nas universidades brasileiras, em razão do elevado prestígio social. Além disso, parece corroborar com as mesmas tendências encontradas por Cunha (2006) e Garcia e Jesus (2015) sobre o elevado desempenho dos cotistas de medicina na UFBA. 


\section{PESQUISAS NAS UNIVERSIDADES ESTADUAIS DA REGIÃO SUL}

A Região Sul do Brasil possui nove Universidades Estaduais, distribuídas em número de sete no Paraná, uma em Santa Catarina e uma no Rio Grande do Sul. Ao revisar a literatura, não foram encontradas pesquisas que discutiram as Estaduais de Santa Catarina e Rio Grande do Sul. Da mesma forma, se o estado do Paraná é o que possui a maior concentração de Universidades Estaduais do país, apenas quatro estudos analisaram três instituições do estado. Contudo, é importante considerar que duas instituições (UNESPAR e UEM) aderiram recentemente às cotas, a partir dos vestibulares de 2019 e 2020 , respectivamente.

Das investigações registradas, o trabalho de Corbari (2018) analisou o desempenho acadêmico, o índice de diplomação e a evasão na UNIOESTE. A partir de informações fornecidas pelo sistema acadêmico, realizou-se um recorte temporal entre as matrículas de 2009 a 2016 de 15 cursos do Campus Cascavel, separando os estudantes entre ampla concorrência e cotistas oriundos de escolas públicas.

Os achados apontam que a média do desempenho acadêmico no período de 2009 a 2016 foi superior entre os cotistas $(59,4)$ em comparação com a concorrência ampla $(56,4)$. Além disso, em 11 cursos os estudantes beneficiários das cotas superaram aos demais, sendo que em apenas quatro cursos as médias dos não cotistas foram menores (Quadro 8).

Quadro 8-Desempenho acadêmico, evasão e diplomação na Universidade Estadual do Oeste do Paraná.

\begin{tabular}{|l|c|c|c|c|c|c|}
\hline \multirow{4}{*}{ Curso } & \multicolumn{2}{|c|}{$\begin{array}{c}\text { Coeficiente de } \\
\text { rendimento entre } \\
\text { 2009-2016 (em 100) }\end{array}$} & $\begin{array}{c}\text { Diplomação (\%) } \\
\text { 2009-2011 }\end{array}$ & \multicolumn{2}{c|}{$\begin{array}{c}\text { Evasão (\%) } \\
\text { 2009-2011 }\end{array}$} \\
\cline { 2 - 7 } & $\begin{array}{c}\text { Cotistas da } \\
\text { rede pública }\end{array}$ & $\begin{array}{c}\text { Sem } \\
\text { cotas }\end{array}$ & $\begin{array}{c}\text { Cotistas da } \\
\text { rede pública }\end{array}$ & $\begin{array}{c}\text { Sem } \\
\text { cotas }\end{array}$ & $\begin{array}{c}\text { Cotistas da } \\
\text { rede pública }\end{array}$ & $\begin{array}{c}\text { Sem } \\
\text { cotas }\end{array}$ \\
\hline Matemática & 36 & 26 & 31,3 & 14,1 & 64,6 & 88,3 \\
\hline Engenharia Agrícola & 45 & 40 & 44,9 & 23 & 44,9 & 64,9 \\
\hline Economia & 50 & 41 & 26,7 & 20 & 48,3 & 63,3 \\
\hline Biologia & 52 & 48 & 47,4 & 34,7 & 45,3 & 54,2 \\
\hline Letras & 56 & 53 & 53,6 & 46,4 & 41,1 & 47,6 \\
\hline Enfermagem & 56 & 59 & 55,1 & 58,9 & 34,7 & 37 \\
\hline Contabilidade & 71 & 59 & 70,8 & 44,4 & 25 & 50 \\
\hline Farmácia & 69 & 63 & 66 & 75,3 & 14,9 & 17,8 \\
\hline Pedagogia & 68 & 65 & 73,5 & 58,2 & 25,5 & 33,3 \\
\hline Fisioterapia & 70 & 67 & 70,8 & 70,8 & 20,8 & 25 \\
\hline Odontologia & 75 & 73 & 89,4 & 93,2 & 4,3 & 5,4 \\
\hline Ciência da Computação & 38 & 39 & 36,7 & 24,3 & 55,1 & 36,5 \\
\hline Administração & 62 & 63 & 63,9 & 71,7 & 29,5 & 23,9 \\
\hline Engenharia Civil & 70 & 72 & 85,4 & 75 & 8,3 & 16,7 \\
\hline Medicina & 73 & 79 & 76,1 & 89,8 & 8,7 & 1,3 \\
\hline Total das médias & $\mathbf{5 9 , 4}$ & $\mathbf{5 6 , 4}$ & $\mathbf{5 9}$ & $\mathbf{5 1 , 5}$ & $\mathbf{3 2 , 3}$ & $\mathbf{3 8 , 3}$ \\
\hline
\end{tabular}

Fonte: adaptado de Corbari (2018). 
A superioridade no desempenho acadêmico também foi acompanhada por uma maior taxa de diplomação dos cotistas (59\%) em comparação com a ampla concorrência $(51,5 \%)$, reproduzindo a mesma tendência registrada nos estudos de Bezerra e Gurgel (2011) e Mendes Junior (2014) sobre a UERJ. Não menos diferente da literatura foi a evasão, menor entre os cotistas $(32,2 \%)$ em relação aos não cotistas (38,3\%) (Quadro 8).

Referente às políticas de cotas na UEL, destacam-se as investigações de Gabriel (2013), e o trabalho de Silva e Pacheco (2013). A análise de Gabriel (2013) partiu de um caso único, o curso de odontologia, investigando os desempenhos acadêmicos, índices de diplomação e taxa de evasão. Foi realizado um retrospecto dos ingressantes no período de 2005 a 2010, divididos em estudantes de ampla concorrência, cotistas de escolas públicas e cotistas negros.

No que se refere ao desempenho acadêmico, os resultados mostraram que nas três modalidades de ingresso os estudantes apresentaram rendimentos superiores à média para a aprovação nas disciplinas (mínimo de 6 pontos). Quando da comparação dos grupos, observou-se que os estudantes de ampla concorrência obtiveram uma média maior $(7,3)$ do que os cotistas de escolas públicas $(7,1)$ e cotistas negros (7). As notas também refletiram nos índices de diplomação: enquanto $91 \%$ dos estudantes de ampla concorrência graduaram-se no tempo mínimo do curso (5 anos), esses percentuais reduziram para $84 \%$ entre os cotistas de escolas públicas, e $57 \%$ entre os cotistas negros (Quadro 9).

Quadro 9-Desempenho, evasão e diplomação em Odontologia da Universidade Estadual de Londrina.

\begin{tabular}{|l|c|c|c|c|c|c|c|c|c|}
\hline \multirow{3}{*}{ Curso } & \multicolumn{3}{|c|}{$\begin{array}{c}\text { Coeficiente de } \\
\text { rendimento entre } \\
2005-2010\end{array}$} & \multicolumn{2}{c|}{$\begin{array}{c}\text { Evasão (\%) entre } \\
2005-2012\end{array}$} & \multicolumn{2}{c|}{$\begin{array}{c}\text { Diplomação (\%) } \\
\text { entre 2005-2012 }\end{array}$} \\
\cline { 2 - 10 } & $\begin{array}{l}\text { Cotistas } \\
\text { da rede } \\
\text { pública }\end{array}$ & $\begin{array}{l}\text { Cotistas } \\
\text { negros }\end{array}$ & $\begin{array}{c}\text { Sem } \\
\text { cotas }\end{array}$ & $\begin{array}{l}\text { Cotistas } \\
\text { da rede } \\
\text { pública }\end{array}$ & $\begin{array}{l}\text { Cotistas } \\
\text { negros }\end{array}$ & $\begin{array}{c}\text { Sem } \\
\text { cotas }\end{array}$ & $\begin{array}{c}\text { Cotistas } \\
\text { da rede } \\
\text { pública }\end{array}$ & $\begin{array}{l}\text { Cotistas } \\
\text { negros }\end{array}$ & $\begin{array}{c}\text { Sem } \\
\text { cotas }\end{array}$ \\
\hline Odontologia & 7,3 & 7 & 7,4 & 2 & 0 & 14 & 84 & 57 & 91 \\
\hline
\end{tabular}

Fonte: adaptado de Gabriel (2013).

Porém, os índices de evasão, apesar de baixos no curso de odontologia, indicaram que os estudantes de ampla concorrência foram os que mais evadiram (14\%) em comparação com os cotistas de escolas públicas (2\%).Já entre os cotistas negros, não houve registro de evasão no período analisado. Os dados parecem reforçar as hipóteses de estudos anteriores, que em determinados cursos, mesmo quando os cotistas apresentam menores desempenhos, os seus índices de evasão são melhores, o que nos permite inferir que ocorre, por parte dos cotistas, a valorização da oportunidade adquirida a partir das políticas afirmativas (Quadro 9).

Em uma perspectiva mais ampla, o trabalho de Silva e Pacheco (2013), na mesma instituição, analisou o desempenho acadêmico e a evasão em nove cursos definidos por alta, média e baixa concorrência. Para a compreensão do desempenho 
acadêmico, utilizou-se do recorte dos ingressantes das turmas de 2005, 2008 e 2011, realizando-se assim, a média do coeficiente de rendimento entre os cotistas e ampla concorrência, após o final do primeiro e do quarto anos de cada turma.

Os dados apontam que a média dos cotistas ingressantes dos nove cursos analisados se manteve satisfatória, ou seja, na média necessária para aprovação semestral, oscilando de 6,6 (menor média) na turma dos ingressantes de 2008, e 7,3 nas turmas dos ingressantes de 2005 após o quarto ano. No entanto, ao comparar o desempenho acadêmico com os estudantes de ampla concorrência, observou-se que nas três turmas analisadas as médias dos noves cursos foram menores, com significativas diferenças nas turmas de 2008 (cotistas 6,7 e ampla concorrência 7,3), e 2011 (cotistas 6,8 e ampla concorrência 7,4) (Quadro 10).

Quadro 10-Desempenho Acadêmico em treze cursos da Universidade Estadual de Londrina.

\begin{tabular}{|c|c|c|c|c|c|c|c|c|c|c|c|c|}
\hline \multirow{2}{*}{ Curso } & \multicolumn{2}{|c|}{$\begin{array}{c}\text { Coeficiente } \\
\text { de } \\
\text { rendimento } \\
2005.1\end{array}$} & \multicolumn{2}{|c|}{$\begin{array}{c}\text { Coeficiente } \\
\text { de } \\
\text { rendimento } \\
2005.4\end{array}$} & \multicolumn{2}{|c|}{$\begin{array}{l}\text { Coeficiente } \\
\text { de } \\
\text { rendimento } \\
2008.1\end{array}$} & \multicolumn{2}{|c|}{$\begin{array}{l}\text { Coeficiente } \\
\text { de } \\
\text { rendimento } \\
2008.4\end{array}$} & \multicolumn{2}{|c|}{$\begin{array}{l}\text { Coeficiente } \\
\text { de } \\
\text { rendimento } \\
2011.1\end{array}$} & \multicolumn{2}{|c|}{$\begin{array}{c}\text { Evasão } \\
\text { acumulada } \\
\text { entre 2005- } \\
2011\end{array}$} \\
\hline & ن⿺辶ّ & 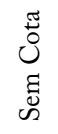 & ن⿺辶ّ & 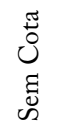 & ن & 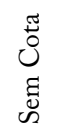 & 芯 & 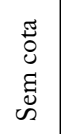 & ల్లు & 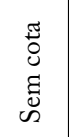 & ن & घี \\
\hline Medicina & 8,1 & 8,3 & 8,1 & 8,2 & 8 & 8,3 & 8,2 & 8,4 & 8 & 8,4 & - & - \\
\hline $\begin{array}{l}\text { Engenharia } \\
\text { Civil }\end{array}$ & 5,4 & 6,3 & 5,4 & 6,7 & 6,2 & 6,6 & 6,1 & 6,5 & 7,1 & 7,2 & - & - \\
\hline Direito & 8,1 & 8,3 & 7,4 & 8 & 7,1 & 7,6 & 7 & 7,6 & 8,5 & 8,5 & - & - \\
\hline Administração & 7,6 & 8,1 & 7,3 & 7,8 & 7,2 & 7,5 & 6,9 & 7,3 & 6,9 & 7,3 & - & - \\
\hline $\begin{array}{l}\text { Ciência da } \\
\text { Computação }\end{array}$ & 5,5 & 5,5 & 5,9 & 6,5 & 4,2 & 5,4 & 4 & 5,7 & 4,8 & 6,5 & - & - \\
\hline Fisioterapia & 7,3 & 7,4 & 7,9 & 8 & 7,2 & 7,6 & 7,6 & 7,7 & 7,3 & 7 & - & - \\
\hline Arquivologia & 8,3 & 8,4 & 8,1 & 8,1 & 7 & 7,8 & 6, & 7,6 & 6,2 & 7,5 & - & - \\
\hline $\begin{array}{l}\text { Ciência do } \\
\text { Esporte }\end{array}$ & 7,5 & 7,8 & 7,4 & 7,6 & 6,4 & 7 & 6,6 & 7 & 6,5 & 6,5 & - & - \\
\hline Letras & 8,2 & 8 & 8,3 & 8,2 & 7,3 & 8,1 & 6,9 & 7,9 & 5,9 & 8,3 & & \\
\hline Média Total & 7,3 & 7,5 & 7,3 & 7,6 & 6,7 & 7,3 & 6,6 & 7,3 & 6,8 & 7,4 & 6,4 & 9,5 \\
\hline
\end{tabular}

Fonte: Silva e Pacheco (2013, p. 92).

Referente às questões de evasão, a pesquisa analisou a taxa entre os anos de 2005 e 2011, comparando-os por modalidades de ingresso. Observou-se a mesma tendência da literatura, na qual em todos os anos os cotistas apresentaram menores índices $(6,4 \%)$ em comparação com os estudantes de ampla concorrência $(9,5 \%)$, reforçando a tese de Mendes Junior (2014), em que mesmo nas situações em que apresentam resultados de desempenho inferiores aos estudantes de ampla concor- 
rência, os cotistas atribuem alto valor ao curso em que ingressam, mantendo assim, menores taxas de evasão (Quadro 10).

Por fim, ressalta-se o estudo de Souza (2012), que analisou o rendimento acadêmico e os índices de evasão dos ingressantes entre 2007 e 2009 de 39 cursos da UEPG. Em termos metodológicos, recorreu-se aos relatórios internos da instituição sobre a avaliação das políticas de cotas, dividindo os estudantes entre cotistas de escolas públicas, cotistas negros e ampla concorrência.

Os achados indicaram que a média acumulada dos cotistas oriundos de escolas públicas foi superior $(6,3)$ aos estudantes de ampla concorrência $(6,1)$. Já estudantes cotistas negros, apresentam as menores médias entre os três grupos $(5,7)$, não obstante a diferença situar-se na região de normalidade da distribuição das notas, uma vez que 70\% dos acadêmicos obtiveram média entre 5,7 e 6,3 (Quadro 11).

\section{Quadro 11 - Rendimento acadêmico e taxas} de evasão na Universidade Estadual de Ponta Grossa.

\begin{tabular}{|l|c|c|c|c|c|c|}
\hline \multirow{2}{*}{39 cursos } & \multicolumn{3}{|c|}{$\begin{array}{c}\text { Coeficiente de } \\
\text { rendimento (total 10,00) } \\
\text { entre 2007-2009 }\end{array}$} & \multicolumn{3}{c|}{$\begin{array}{c}\text { Taxas de evasão (\%) } \\
\text { entre 2007-2009 }\end{array}$} \\
\cline { 2 - 7 } & $\begin{array}{c}\text { Cotistas da } \\
\text { rede pública }\end{array}$ & $\begin{array}{c}\text { Cotistas } \\
\text { negros }\end{array}$ & $\begin{array}{c}\text { Sem } \\
\text { cotas }\end{array}$ & $\begin{array}{c}\text { Cotistas da } \\
\text { rede pública }\end{array}$ & $\begin{array}{c}\text { Cotistas } \\
\text { negros }\end{array}$ & $\begin{array}{c}\text { Sem } \\
\text { cotas }\end{array}$ \\
\hline Ingressantes de 2007 & 6,4 & 5,4 & 6,1 & 13,5 & 15,8 & 14,5 \\
\hline Ingressantes de 2008 & 6,2 & 5,9 & 5,9 & 6,1 & 4,3 & 4,8 \\
\hline Ingressantes de 2009 & 6,2 & 5,7 & 6,3 & 3,3 & 5,6 & 6,1 \\
\hline Média Geral & $\mathbf{6 , 3}$ & $\mathbf{5 , 7}$ & $\mathbf{6 , 1}$ & $\mathbf{7 , 6}$ & $\mathbf{8 , 5}$ & $\mathbf{8 , 4}$ \\
\hline
\end{tabular}

Fonte: adaptado de Souza (2012).

Quanto às taxas de evasão, apesar dos baixos percentuais, observou-se que as variações se mantiveram próximas entre as três categorias, sendo os cotistas de escolas públicas com menores percentuais acumulados durante os três anos $(7,6 \%)$ em comparação com os estudantes de ampla concorrência $(8,4 \%)$ e cotistas negros (8,5\%) (Quadro 11).

Com base nos dados, é possível inferir que as políticas de cotas na UEPG revelam que os cotistas vêm se desempenhando satisfatoriamente, sinalizando que quando a igualdade de oportunidades ocorre, a possibilidade da igualdade de resultados se eleva, o que tende a favorecer a redução das desigualdades educacionais (Souza, 2012).

\section{PESQUISAS REFERENTES ÀS UNIVERSIDADES ESTADUAIS DA REGIÃO CENTRO-OESTE}

A região Centro-Oeste registra três Universidades Estaduais, distribuídas por três estados. Nesse âmbito, encontramos três estudos, sendo um sobre a UNEMAT e dois destinados à realidade da UEMS. Referente à UNEMAT encontrou-se o estudo de Costa (2015), que analisou as taxas de diplomação e evasão da instituição. 
A partir de dados gerados junto à secretaria acadêmica da instituição, avaliou-se o desempenho dos ingressantes de 2005/2 a 2011/02, em 12 cursos do campus de Cáceres.

Observou-se que, no Campus Cáceres, os estudantes da ampla concorrência apresentaram maiores percentuais de diplomação frente aos cotistas. As exceções foram os cursos de pedagogia (Sinop) e enfermagem (Cáceres), nos quais os cotistas obtiveram maiores índices de diplomação do que a ampla concorrência (Quadro 12).

Quadro 12 - Índice de diplomação e evasão no Campus Cáceres/Universidade Estadual de Mato Grosso.

\begin{tabular}{|l|c|c|c|c|}
\hline Campus Cáceres & \multicolumn{2}{|c|}{ Índice de diplomação (\%) } & \multicolumn{2}{|c|}{ Taxa de evasão (\%) } \\
\hline Cursos & $\begin{array}{c}\text { Estudantes } \\
\text { Cotas }\end{array}$ & $\begin{array}{c}\text { Ampla } \\
\text { concorrência }\end{array}$ & $\begin{array}{c}\text { Estudantes } \\
\text { Cotas }\end{array}$ & $\begin{array}{c}\text { Ampla } \\
\text { concorrência }\end{array}$ \\
\hline Agronomia & 11,8 & 48 & 13,3 & 13,7 \\
\hline Biologia & 12,5 & 49,5 & 23,5 & 34,4 \\
\hline Ciências Contábeis & 38,7 & 47,3 & 17,1 & 27,5 \\
\hline Computação & 15,8 & 34,5 & 34,9 & 34,9 \\
\hline Direito & 46,6 & 58,1 & 9 & 18,7 \\
\hline Educação Física & 47,5 & 56,9 & 10 & 10,6 \\
\hline Enfermagem & 60,4 & 55,6 & 5,9 & 8,1 \\
\hline Geografia & 13,1 & 47,2 & 10,7 & 30,3 \\
\hline História & 21 & 31,7 & 23,1 & 42,7 \\
\hline Letras & 26,6 & 53,2 & 28,4 & 28,1 \\
\hline Matemática & 16,2 & 29,2 & 47,7 & 40,8 \\
\hline Pedagogia & 62 & 82,1 & 9,8 & 21,1 \\
\hline Média Total & $\mathbf{3 1 , 7}$ & $\mathbf{5 0 , 3}$ & $\mathbf{1 8 , 5}$ & $\mathbf{2 6 , 1}$ \\
\hline
\end{tabular}

Fonte: adaptado de Costa (2015).

Uma hipótese para essa realidade se deve às particularidades regionais da cidade. Marcada por uma forte tradição agrária e um mercado de trabalho dinâmico, os períodos de colheita de soja demandam tempo daqueles estudantes de baixa renda, que necessitam de trabalho para o sustento familiar. Somado a esse fator, a instituição já possuía uma oferta baixa de bolsas de apoio, extensão e pesquisa. Com a chegada dos cotistas, público que necessitava de especial atenção, as políticas internas da UNEMAT não deram conta de atender às demandas específicas desse público, o que pode ter interferido no menor desempenho dos cotistas em relação à ampla concorrência (Costa, 2015).

No entanto, no que se refere às taxas de evasão, essa tendência se inverteu. Os cotistas apresentaram menores índices de evasão em praticamente todos os cursos analisados, o que reforça as conclusões de estudos anteriores, ou seja, mesmo nos casos com menores desempenhos acadêmicos, a valorização da vaga tende a ser maior nesse grupo de beneficiários. 
Quanto à realidade da UEMS, o primeiro estudo é o de Cordeiro (2008), que pesquisou o rendimento acadêmico, evasão e diplomação dos discentes de 37 cursos da instituição, matriculados entre 2004 e 2007.

Em termos metodológicos, utilizou-se de uma análise longitudinal, dividindo em três grandes áreas do saber (Ciências Agrárias/Saúde; Ciências Humanas e Ciências Exatas/Tecnológicas). Em seguida, comparou o desempenho de estudantes ingressantes do vestibular de 2004 e que concluíram o curso no final de 2007, nas seguintes modalidades de ingressos: Ampla concorrência, cotistas negros e cotistas indígenas.

Enquanto resultados, observou-se que o desempenho acadêmico dos estudantes cotistas negros $(6,5)$ apresentou a mesma média que a ampla concorrência $(6,5)$ na somatória das três áreas do saber, sendo, inclusive, superiores nas Ciências Agrárias e Humanas. No entanto, referente aos beneficiários indígenas, os rendimentos se mostraram bem abaixo da média $(3,7)$ em todas as três áreas do saber (Quadro 13).

Quadro 13 - Rendimento, evasão e diplomação entre 20042007 na Universidade Estadual do Mato Grosso do Sul.

\begin{tabular}{|l|c|c|c|c|c|c|c|c|c|}
\hline \multirow{2}{*}{$\begin{array}{l}\text { Área do } \\
\text { Saber }\end{array}$} & \multicolumn{3}{|c|}{$\begin{array}{c}\text { Média acadêmica } \\
\text { entre 2004 a } 2007\end{array}$} & \multicolumn{3}{|c|}{$\begin{array}{l}\text { Taxa de Diplomação } \\
\text { (\%) no final de 2007 }\end{array}$} & \multicolumn{3}{|c|}{$\begin{array}{c}\text { Índice de Evasão } \\
\text { (\%) }\end{array}$} \\
\cline { 2 - 11 } & $\begin{array}{c}\text { Cotistas } \\
\text { Negros }\end{array}$ & $\begin{array}{c}\text { Cotistas } \\
\text { Indígenas }\end{array}$ & $\begin{array}{c}\text { Sem } \\
\text { Cotas }\end{array}$ & $\begin{array}{c}\text { Cotistas } \\
\text { Negros }\end{array}$ & $\begin{array}{c}\text { Cotistas } \\
\text { Indígenas }\end{array}$ & $\begin{array}{c}\text { Sem } \\
\text { Cotas }\end{array}$ & $\begin{array}{c}\text { Cotistas } \\
\text { Negros }\end{array}$ & $\begin{array}{c}\text { Cotistas } \\
\text { Indigenas }\end{array}$ & $\begin{array}{c}\text { Sem } \\
\text { Cotas }\end{array}$ \\
\hline $\begin{array}{l}\text { Ciências } \\
\text { Agrárias, } \\
\text { Biológicas e } \\
\text { Saúde }\end{array}$ & 6,7 & 3,3 & 6,6 & - & - & - & 48,3 & 85,7 & 27,3 \\
\hline $\begin{array}{l}\text { Ciências } \\
\text { Humanas e } \\
\text { Sociais }\end{array}$ & 8,1 & 6,6 & 8 & - & - & - & 40,7 & 65,8 & 18,4 \\
\hline $\begin{array}{l}\text { Ciências } \\
\text { Exatas e } \\
\text { Tecnológicas }\end{array}$ & 4,7 & 1,1 & 4,9 & - & - & - & 73,2 & 100 & 59,3 \\
\hline $\begin{array}{l}\text { Percentual } \\
\text { Acumulado }\end{array}$ & $\mathbf{6 , 5}$ & $\mathbf{3 , 7}$ & $\mathbf{6 , 5}$ & $\mathbf{2 0 , 7}$ & $\mathbf{1 1 , 9}$ & $\mathbf{2 8 , 6}$ & $\mathbf{5 4}$ & $\mathbf{8 3 , 3}$ & $\mathbf{3 5}$ \\
\hline
\end{tabular}

Fonte: adaptado de Cordeiro (2008).

Também foram observadas entre os indígenas médias mais baixas nos índices de diplomação: enquanto a ampla concorrência e os cotistas negros apresentaram taxa de diplomação de 28,7 e 20,6\% respectivamente, esses números caíram para $11,9 \%$ entre os beneficiários indígenas. Quanto às taxas de evasão, os achados divergem significativamente da realidade das outras instituições estaduais. Os números mostraram que cotistas negros $(54 \%)$ e indígenas $(83,3 \%)$ registraram os maiores abandonos em todas as áreas, em comparação com a ampla concorrência (35\%) (Quadro 13). 
Em um estudo mais recente na mesma instituição, Benatti (2017) ampliou o universo da pesquisa, analisando as taxas de evasão em todos os 15 campi, no ano de 2014. Ao recorrer aos dados internos fornecidos pela UEMS, a autora encontrou achados que divergem das tendências do estudo de Cordeiro (2008). Observou-se que, especificamente no campus de Dourados, os cotistas indígenas foram os que apresentaram os menores índices de evasão (26\%) em comparação com os cotistas negros $(33,8 \%)$ a ampla concorrência $(32,7 \%)$. Ainda, se as diferenças entre esses dois últimos grupos eram grandes no estudo de Cordeiro (2008) entre 2004 e 2007, os percentuais reduziram-se a valores inexpressivos (1,1\%) em 2014 (Quadro 14).

\section{Quadro 14 - Evasão em 15 Campi da Universidade Estadual do Mato Grosso do Sul no ano de 2014.}

\begin{tabular}{|l|c|c|c|}
\hline \multirow{2}{*}{ Campus } & \multicolumn{3}{|c|}{ Índice de Evasão (\%) em 2014 } \\
\cline { 2 - 4 } & Cotistas Negros & Cotistas Indígenas & Sem Cotas \\
\hline Amambaí & 33,3 & 0 & 36,4 \\
\hline Aquidauana & 5,8 & 0 & 9,3 \\
\hline Campo Grande & 46,9 & 54,5 & 49,5 \\
\hline Cassilândia & 37,5 & - & 28,5 \\
\hline Coxim & 14,2 & - & 53,3 \\
\hline Dourados & 33,8 & 26 & 32,7 \\
\hline Glória de Dourados & 100 & 80 & 51,1 \\
\hline Ivinhema & 50 & - & 41,9 \\
\hline Jardim & 42,8 & 50 & 24,2 \\
\hline Maracaju & 36,3 & 0 & 26,1 \\
\hline Mundo Novo & 23 & 100 & 57,6 \\
\hline Naviraí & 36,3 & 50 & 38,8 \\
\hline Nova Andradina & 54,5 & - & 45,4 \\
\hline Paranaíba & 16,6 & 0 & 34,2 \\
\hline Ponta Porã & 27,2 & - & 41,6 \\
\hline Percentual Acumulado & $\mathbf{3 7 , 2}$ & $\mathbf{3 6}$ & $\mathbf{3 8}$ \\
\hline
\end{tabular}

Fonte: adaptado de Benatti (2017).

Da mesma forma, ao comparar as taxas de evasão no somatório dos 15 Campi da instituição, observou-se que a taxa de evasão foi maior entre os estudantes de ampla concorrência (38\%), em comparação com os estudantes negros $(37,2 \%)$ e cotistas indígenas, sendo esses últimos com os menores números apresentados (36\%) (Quadro 14).

A pesquisa de Benatti (2017) parece ilustrar uma mudança na evasão do Campus Dourado, ao longo de quase uma década. Apesar de não termos encontrado explicações no estudo da autora que justifiquem essas evoluções, os atuais 
resultados reforçam a tendência das demais universidades estaduais registradas anteriormente, na qual os cotistas têm feito jus às oportunidades que obtiveram, no quesito aproveitamento de vagas no ensino superior.

\section{PESQUISAS REFERENTES ÀS UNIVERSIDADES ESTADUAIS DA REGIÃO NORDESTE}

A Região Nordeste é a que registra o maior número de Universidades Estaduais; quinze instituições, distribuídas por oito estados. Dessas, todas aderiram às políticas de cotas, sendo algumas tardiamente, como a UVA e a URCA, em 2018, e outras com percentuais reduzidos de vagas reservadas, a exemplo da UEMASUL (15\%), a UPE (20\%) e a UESPI (30\%).

Em contrapartida, registraram-se apenas dois trabalhos que se destinaram às experiências pioneiras da UNEB. A primeira investigação, de Santos (2007), pesquisou o desempenho acadêmico de cotistas e ampla concorrência dos vestibulares de 2003. Em termos metodológicos, recorreu-se aos dados primários nos diários de classe dos cursos de 14 departamentos localizados em diversos Campi da Instituição.

Ao realizar o cálculo das médias de coeficiente de rendimento na graduação, observou-se que não há diferenças das médias semestrais entre cotistas e não cotistas. Enquanto a somatória dos 14 Campi apontou para um desempenho médio de 7,7, os não cotistas registraram 7,8 (Quadro 15).

Quadro 15 - Rendimento acadêmico dos ingressantes de 2003 na Universidade do Estado da Bahia.

\begin{tabular}{|l|c|c|}
\hline \multirow{2}{*}{ Grandes Áreas do Saber } & \multicolumn{2}{|c|}{ Coeficiente de } \\
& \multicolumn{2}{|c|}{ rendimento acadêmico em 2003 } \\
\cline { 2 - 3 } & Cotistas & Sem cotas \\
\hline Ciências Exatas - Campus I & 7,3 & 7,4 \\
\hline Ciências Humanas - Campus I & 7,7 & 7,8 \\
\hline Ciências da Vida - Campus I & 7,4 & 7,8 \\
\hline Educação - Campus I & 8,6 & 8,5 \\
\hline Ciências Exatas - Campus II & 8,2 & 8,4 \\
\hline Educação - Campus II & 8,1 & 8 \\
\hline Tecnologia e Ciências Sociais - Campus II & 6,7 & 7,3 \\
\hline Ciências Humanas - Campus III & 7,5 & 7,8 \\
\hline Ciências Humanas - Campus IV & 7,6 & 7,8 \\
\hline Ciências Humanas - Campus V & 8,2 & 8,3 \\
\hline Ciências Humanas - Campus VI & 7,8 & 8 \\
\hline Educação - Campus VII & 7,6 & 7,6 \\
\hline Ciências Humanas - Campus VIII & 7 & 7,1 \\
\hline Educação - Campus X & 8,4 & 8,6 \\
\hline Média Total & $\mathbf{7 , 7}$ & $\mathbf{7 , 8}$ \\
\hline
\end{tabular}

Fonte: adaptado de Santos (2007, p. 117). 
Os cotistas apresentaram valores maiores do que os estudantes de ampla concorrência em alguns departamentos, como no caso dos cursos de Educação-Campus I (cotistas 8,6 e ampla concorrência 8,5) e Educação-Campus II (cotistas 8,1 e ampla concorrência 8) (Quadro 16). Dessa forma, Santos (2007) conclui que os dados refutam, na realidade da UNEB, a conjectura de que os beneficiários não teriam condições de acompanhar os cursos e apresentariam menor aproveitamento nas disciplinas do que os demais estudantes.

Por um caminho metodológico distinto, a pesquisa de Mattos, Macedo e Mattos (2013) se aproximou dos achados na mesma instituição. Em termos metodológicos, utilizaram de uma análise longitudinal, mensurando os rendimentos acadêmicos de nove cursos distribuídos em três Campi da instituição, entre os anos de 2003 a 2009.

Constatou-se que o desempenho acadêmico dos discentes optantes pelo sistema de cotas variou em relação ao estudante não optante. Todavia, essa variação se deu sem um padrão determinado, não havendo uma regularidade capaz de despertar avaliações hierarquizantes (Quadro 16).

Quadro 16 - Performance geral dos estudantes da

Universidade do Estado da Bahia - 2005 a 2009.

\begin{tabular}{|l|c|c|}
\hline \multirow{2}{*}{ Curso } & \multicolumn{2}{|c|}{$\begin{array}{c}\text { Coeficiente de rendimento } \\
\text { acadêmico 2005-2009 }\end{array}$} \\
\cline { 2 - 3 } & Cotistas & Sem cotas \\
\hline Administração em Marketing - Campus V & 7,8 & 7,9 \\
\hline Administração em Microempresas - Campus V & 7,8 & 7,9 \\
\hline História - Campus V & 7,8 & 7,6 \\
\hline Sistema de Informação - Campus I & 6,5 & 7 \\
\hline Pedagogia em Gestão - Campus I & 8,2 & 8,1 \\
\hline Pedagogia em Educação Infantil - Campus I & 8,3 & 8,2 \\
\hline Direito - Campus III & 7,7 & 7,9 \\
\hline Pedagogia em Docência - Campus III & 8,3 & 8,1 \\
\hline Pedagogia em Comunicação - Campus III & 8 & 8,1 \\
\hline Total & $\mathbf{7 , 8 2}$ & $\mathbf{7 , 8 6}$ \\
\hline
\end{tabular}

Fonte: adaptado de Mattos, Macedo e Mattos (2013).

Merecem ainda destaque os cursos de História, Pedagogia em Gestão, e Pedagogia em educação infantil, nos quais os cotistas apresentaram resultados superiores à ampla concorrência (Quadro 16). Assim, o resultado da pesquisa configura-se como respostas às correntes contrárias ao sistema de cotas para negros na UNEB, quando afirmavam que os cotistas diminuiriam o nível de desempenho acadêmico da instituição (Mattos, Macedo e Mattos, 2013).

Feitas as considerações, ressalta-se que apesar da relevância dos estudos apresentados, a sua representatividade ainda é baixa — apenas dois trabalhos para o 
universo de 15 Universidades Estaduais na Região Nordeste. Mais emblemática é a Região Norte que, apesar de possuir cinco Universidades Estaduais distribuídas por cinco estados, não conta com nenhuma investigação sobre as avaliações afirmativas nessas universidades.

Se considerarmos as particularidades do perfil étnico da região, bem como, o fato de que todas as cinco instituições já terem aderido às políticas de cotas (ainda que tardiamente, como o caso da UERR, no ano de 2018), a ausência de estudos restringe a devida comparação com as demais instituições e dificulta a sistematização de políticas públicas, necessárias para a sua continuidade.

\section{DISCUSSÃO E ANÁLISE DOS DADOS}

Identificamos junto à literatura a presença de 15 trabalhos que discutiram as avaliações das políticas afirmativas nas universidades estaduais (Quadro 17). Os resultados encontrados indicam que não se observou, em sua maioria, distinções significativas entre a média do rendimento acadêmico entre os estudantes. As diferenças ocorreram entre áreas do saber, oscilando de acordo com a realidade de cada curso e instituição (Bezerra e Gurgel, 2011; Brandão e Matta, 2007; Barros, 2010; Gabriel, 2013; Souza, 2012; Cordeiro, 2008; Santos, 2007; Mattos, Macedo e Mattos, 2013).

Ademais, mesmo no grupo de autores (quatro trabalhos) que sublinharam diferenças entre os desempenhos dos estudantes, as oscilações ocorreram ora a favor dos estudantes da ampla concorrência (Mendes Junior, 2014; Silva e Pacheco, 2013), ora entre determinadas categorias de cotas (Cicalò, 2008; Corbari, 2018).

Ao comparar as diferenças, em alguns casos, é possível inferir que se relacionam com os distintos percursos escolhidos. Os exemplos da UERJ e as quatro pesquisas sobre ela realizadas (Bezerra e Gurgel, 2011; Cicalò, 2008; Mendes Junior, 2014; Machado, 2013), das duas pesquisas sobre a UEL (Gabriel, 2013; Silva e Pacheco, 2013), e das duas investigações sobre a UEMS (Cordeiro, 2008; Benatti, 2017), ilustram as divergências nos achados oriundas de diferentes metodologias adotadas.

Apesar das múltiplas interpretações no processo avaliativo, os dados balizam que os cotistas têm contrariado as expectativas de menor rendimento acadêmico, mostrando-se capazes de acompanhar os demais colegas e, em alguns casos, obtendo notas inclusive superiores às deles durante a graduação (Cicalò, 2008; Corbari, 2018).

No que se refere aos índices de evasão, grande parte dos estudos identificou maior taxa entre os estudantes de ampla concorrência (Bezerra e Gurgel, 2011; Cicalò, 2008; Mendes Junior, 2014; Machado, 2013; Corbari, 2018; Silva e Pacheco, 2013; Gabriel, 2013; Costa, 2015; Benatti, 2017). Ainda que não se trate de um censo da evasão em todos os cursos das 44 Universidades Estaduais, os dados enfraquecem os argumentos sobre os cotistas enquanto grupo mais propenso à evasão.

Atinentes às taxas de diplomação, seis trabalhos abordaram a temática, ilustrando que os resultados foram equitativos entre os grupos analisados. Desse modo, enquanto três estudos apontaram para os melhores rendimentos dos cotistas (Mendes Junior, 2014; Machado, 2013; Corbari, 2018), outras investigações apon- 
Quadro 17 - Síntese do balanço das avaliações nas estaduais do Brasil.

\begin{tabular}{|c|c|c|c|c|c|}
\hline Autor & $\begin{array}{c}\text { Tipo do } \\
\text { trabalho }\end{array}$ & Universidade & $\begin{array}{l}\text { Rendimento } \\
\text { acadêmico }\end{array}$ & $\begin{array}{c}\text { Índice de } \\
\text { evasão }\end{array}$ & $\begin{array}{c}\text { Taxa de } \\
\text { diplomação }\end{array}$ \\
\hline $\begin{array}{l}\text { Bezerra e } \\
\text { Gurgel (2011) }\end{array}$ & Artigo & UERJ & $\begin{array}{c}\text { Não houve } \\
\text { diferenças } \\
\text { significativas }\end{array}$ & $\begin{array}{l}\text { Menor para } \\
\text { os cotistas }\end{array}$ & Não analisado \\
\hline Cicalò (2008) & Artigo & UERJ & $\begin{array}{c}\text { Maior para os } \\
\text { cotistas }\end{array}$ & $\begin{array}{l}\text { Menor para } \\
\text { os cotistas }\end{array}$ & Não analisado \\
\hline $\begin{array}{l}\text { Mendes Junior } \\
\text { (2014) }\end{array}$ & Artigo & UERJ & $\begin{array}{c}\text { Maior } \\
\text { para ampla } \\
\text { concorrência }\end{array}$ & $\begin{array}{l}\text { Menor para } \\
\text { os cotistas }\end{array}$ & $\begin{array}{l}\text { Maior para os } \\
\text { cotistas }\end{array}$ \\
\hline $\begin{array}{l}\text { Machado } \\
(2013)\end{array}$ & Livro & UERJ & Não analisado & $\begin{array}{l}\text { Menor para } \\
\text { os cotistas }\end{array}$ & $\begin{array}{l}\text { Maior para os } \\
\text { cotistas }\end{array}$ \\
\hline $\begin{array}{l}\text { Brandão e } \\
\text { Matta (2007) }\end{array}$ & Livro & UENF & $\begin{array}{c}\text { Não houve } \\
\text { diferenças } \\
\text { significativas }\end{array}$ & $\begin{array}{c}\text { Não houve } \\
\text { diferenças } \\
\text { significativas }\end{array}$ & Não analisado \\
\hline Barros (2010) & Dissertação & UNIMONTES & $\begin{array}{c}\text { Não houve } \\
\text { diferenças } \\
\text { significativas }\end{array}$ & $\begin{array}{c}\text { Não } \\
\text { analisado }\end{array}$ & Não analisado \\
\hline Corbari (2018) & Dissertação & UNIOESTE & $\begin{array}{c}\text { Maior para os } \\
\text { cotistas }\end{array}$ & $\begin{array}{l}\text { Menor para } \\
\text { os cotistas }\end{array}$ & $\begin{array}{l}\text { Maior para os } \\
\text { cotistas }\end{array}$ \\
\hline $\begin{array}{l}\text { Silva e Pacheco } \\
\text { (2013) }\end{array}$ & Livro & UEL & $\begin{array}{c}\text { Maior } \\
\text { para ampla } \\
\text { concorrência }\end{array}$ & $\begin{array}{l}\text { Menor para } \\
\text { os cotistas }\end{array}$ & Não analisado \\
\hline Gabriel (2013) & Dissertação & UEL & $\begin{array}{c}\text { Não houve } \\
\text { diferenças } \\
\text { significativas }\end{array}$ & $\begin{array}{l}\text { Menor para } \\
\text { os cotistas }\end{array}$ & $\begin{array}{l}\text { Maior para } \\
\text { a ampla } \\
\text { concorrência }\end{array}$ \\
\hline Souza (2012) & Dissertação & UEPG & $\begin{array}{c}\text { Não houve } \\
\text { diferenças } \\
\text { significativas }\end{array}$ & $\begin{array}{c}\text { Não houve } \\
\text { diferenças } \\
\text { significativas }\end{array}$ & Não analisado \\
\hline Costa (2015) & Tese & UNEMAT & Não analisado & $\begin{array}{l}\text { Menor para } \\
\text { os cotistas }\end{array}$ & $\begin{array}{c}\text { Maior } \\
\text { para ampla } \\
\text { concorrência }\end{array}$ \\
\hline $\begin{array}{l}\text { Cordeiro } \\
(2008)\end{array}$ & Tese & UEMS & $\begin{array}{c}\text { Não houve } \\
\text { diferenças } \\
\text { significativas }\end{array}$ & $\begin{array}{c}\text { Menor } \\
\text { para ampla } \\
\text { concorrência } \\
\end{array}$ & $\begin{array}{c}\text { Maior } \\
\text { para ampla } \\
\text { concorrência }\end{array}$ \\
\hline Benatti (2017) & Dissertação & UEMS & Não analisado & $\begin{array}{l}\text { Menor para } \\
\text { os cotistas }\end{array}$ & Não analisado \\
\hline Santos (2007) & Livro & UNEB & $\begin{array}{c}\text { Não houve } \\
\text { diferenças } \\
\text { significativas } \\
\text { entre os grupos }\end{array}$ & $\begin{array}{c}\text { Não } \\
\text { analisado }\end{array}$ & Não analisado \\
\hline $\begin{array}{l}\text { Mattos, } \\
\text { Macedo e } \\
\text { Mattos (2013) }\end{array}$ & Artigo & UNEB & $\begin{array}{c}\text { Não houve } \\
\text { diferenças } \\
\text { significativas } \\
\text { entre os grupos }\end{array}$ & $\begin{array}{c}\text { Não } \\
\text { analisado }\end{array}$ & Não analisado \\
\hline
\end{tabular}


taram para a superioridade dos estudantes de ampla concorrência (Gabriel, 2013; Costa, 2015; Cordeiro, 2008).

Assim, é possível inferir que essa geração de cotistas derruba as crenças, não fundadas, de que os beneficiários não só não conseguiriam se manter nas universidades, evadindo em massa, como ainda iriam diminuir o padrão de qualidade do ensino público, com menores rendimentos e baixas taxas de diplomações.

Por serem recentes os primeiros resultados da adoção em massa das cotas nas instituições federais de ensino superior (IFES), torna-se necessário o acúmulo de casos para que seja possível analisar os principais impactos dessa política. Contudo, os resultados aqui sumarizados indicam que os desempenhos de cotistas e não cotistas apresentam pouca diferença significativa, que por consequência, enfraquece os argumentos contrários às cotas pautados numa hipotética perda de qualidade. Ademais, se tomarmos as políticas de cotas como mecanismo de mobilidade social, dada a indissociabilidade entre renda e tempo de estudo, a menor evasão entre os cotistas dá pistas de que esse papel pode se cumprir, além de reduzir os efeitos negativos da evasão sobre a alocação de recursos no ensino superior.

\section{CONSIDERAÇÕES FINAIS}

No intuito de sistematizar as pesquisas que avaliaram o desempenho dos beneficiários das políticas de cotas nas universidades estaduais, o artigo realizou uma revisão integrativa sobre as publicações nacionais em periódicos, dissertações e teses disponíveis nas plataformas online. Se nos primeiros anos de 2000 as narrativas de acadêmicos como Maggie e Fry (2004), e Lewgoy (2005) sustentavam que os favorecidos por cotas reproduziriam menores coeficientes de rendimento e teriam dificuldades financeiras para se sustentar, induzindo-os a abandonarem a educação superior e/ou atrasando a conclusão do curso, os achados da presente pesquisa foram na contramão dessa literatura.

Com base nos 15 estudos analisados, abarcando 12 instituições estaduais, os dados nos permitem afirmar que a implantação das cotas não gerou perda de desempenho nas universidades, dado que os cotistas das universidades analisadas obtiveram rendimentos similares aos demais estudantes, superando-os, inclusive, nos índices de diplomação e nas menores taxas de evasão.

Em contraponto à epígrafe que abre o artigo, os achados desta pesquisa colocam em xeque o suposto menor desempenho dos cotistas, não fundado em dados empíricos. Na mesma lógica, questionamos se não parece contraditório que outro professor universitário, no ano de 2019, publicasse uma matéria em um jornal de apelo popular, afirmando que as cotas são uma política ineficiente, que se move por apelos emotivos, ao invés de racionais? Ora, ao não recorrer a dados empíricos, disponíveis em quase duas décadas de políticas afirmativas no Brasil, não seria ele quem se fundou em argumentos irracionais, movidos por apelos emotivos que condenam uma política sem uma base argumentativa sólida? Até onde o mito da perda da qualidade não é uma forma de camuflar um preconceito social em um país desigual e com uma forte herança escravocrata? 
Portanto, os dados apresentados nesta pesquisa ilustram que a política de cotas nas Universidades estaduais, pelo menos no que se refere ao desempenho acadêmico, têm contrariado os antigos e ainda reticentes argumentos de que a sua implantação causaria danos à própria instituição e queda na qualidade educacional. Também é válido frisar que as discrepâncias apontadas em alguns estudos, indicando um menor desempenho acadêmico de estudantes cotistas, sobretudo em cursos de exatas, dão indícios sobre a necessidade de ampliarmos o debate sobre programas que visem mitigar eventuais deficiências do ensino público, como a expansão dos programas de monitorias ou a adoção de um semestre de nivelamento.

Apesar da relevância supracitada, é importante considerar que as pesquisas sobre as dimensões exploradas neste trabalho não são exaustivas, uma vez que do total de 44 Estaduais no Brasil, o percentual de instituições investigadas ainda corresponde a $31 \%$ do universo destas. Além disso, cabe destacar a ausência de estudos sobre o tema na região Norte, e baixo número de pesquisas no Nordeste, área com o maior número de Universidades Estaduais do Brasil, onde apenas duas investigações foram realizadas. Logo, o desenvolvimento de mais pesquisas nessas regiões se torna fundamental, não só por monitorar sistematicamente a política como por trazer elementos que permitam estudos comparativos sobre as diversas realidades nacionais.

Em conclusão, pode-se afirmar que este trabalho subsidiou informações relevantes para as políticas públicas de cotas na área de educação, fornecendo dados que podem servir como um indicador de acompanhamento, em nível nacional, bem como qualificando a política pública frente a um recente contexto de movimentos negacionistas, propagações de fake nerws e notícias não fundadas em dados científicos.

\section{REFERÊNCIAS}

ARRIGONI, F.J. Gestão pública: busca da igualdade social a partir da ação afirmativa cota no ensino superior brasileiro. Tese (Doutorado em Administração) - Fundação Getulio Vargas, Rio de Janeiro, 2018.

BARROS, F. Uma análise sobre cotas no curso médico da Unimontes: desempenho acadêmico dos estudantes e percepções docentes. Dissertação (Mestrado em Ciências) - Universidade Federal de São Paulo, São Paulo, 2010.

BAYMA, F. Reflexões sobre a constitucionalidade das cotas raciais em universidades públicas do Brasil. Ensaio: Avaliação e Políticas Públicas em Educação, Rio de Janeiro, v. 20, n. 75, p. 325-346, 2012. https://doi.org/10.1590/S010440362012000200006

BENATTI, V. Dificuldade da permanência na UEMS: A realidade do estudante pobre e negro na unidade universitária de Dourados. Dissertação (Mestrado em Sociologia) - Universidade Estadual de Mato Grosso do Sul, Dourados, 2017.

BEZERRA, T. O.; GURGEL, C. A política pública de cotas em universidades, desempenho acadêmico e inclusão social. Sustainable Business International Journal, n. 9, 2011. https://doi.org/10.22409/sbijounal2011.i09.a10187 
BRANDÃO, A.; MATTA, L. Avaliação da política de reserva de vagas na Universidade Estadual do Norte Fluminense: estudo dos alunos que ingressaram em 2003. In: BRANDÃO, A. (org.). Cotas raciais no Brasil: a primeira avaliação. Rio de Janeiro: DP\&A, 2007. p. 48-80.

CALDAS, M.P.; TINOCO, T. Pesquisa em gestão de recursos humanos nos anos 1990: um estudo bibliométrico. Revista de Administração de Empresas, São Paulo, v. 44, n. 3, p. 100-114, 2004. https://doi.org/10.1590/S0034-75902004000300008

CICALÒ, A. What do we know about quotas? Data and considerations about the implementation of the quota system in the State University of Rio de Janeiro. Universitas Humanística, Bogotá, n. 65, p. 261-278, 2008.

CORBARI, E. Avaliação do impacto da política de cotas na Unioeste: quem de fato foi incluído? Dissertação (Mestrado em Ciências Sociais) - Universidade Estadual do Oeste do Paraná, Paraná, 2018.

CORDEIRO, M. J. Negros e Indígenas cotistas da Universidade Estadual do Mato Grosso do Sul: desempenho acadêmico do ingresso à conclusão do curso. Tese (Doutorado em Educação) - Pontifícia Universidade Católica de São Paulo, São Paulo, 2008.

COSTA, J. Cor e ensino superior: trajetórias e experiências de estudantes cotistas da Universidade Estadual do Estado de Mato Grosso. Tese (Doutorado em Sociologia) Universidade Federal de São Carlos, São Carlos, 2015.

CUNHA, E. M. P. Sistema universal e sistema de cotas para negros na Universidade de Brasília: um estudo de desempenho. 98f. Dissertação (Mestrado em Educação) Universidade de Brasília, Brasília, 2006.

FERES JUNIOR, J.; DAFLON, V.T. Ação afirmativa na Índia e no Brasil: um estudo sobre a retórica acadêmica. Sociologias, v. 17, n. 40, p. 92-123, 2015. https://doi. org/10.1590/15174522-017004003

FERRAZ, C. Cotas nas universidades: uma política irracional e insensata. Gazeta do Povo, 2019.

GABRIEL, M. Perfil dos egressos do curso de odontologia da Universidade Estadual de Londrina. Dissertação (Mestrado em Odontologia) - Universidade Estadual de Londrina, Londrina, 2013.

GARCIA, F. A.;JESUS, G. R. Uma avaliação do sistema de cotas raciais da universidade de Brasília. Estudos em Avaliação Educacional, São Paulo, v. 26, n. 61, p. 146-165, 2015. https://doi.org/10.18222/eae266102773

LEAL DA SILVA, G. H. O desempenho e as cotas: o caso da UFSC. Dissertação (Mestrado em Ciências Políticas) - Universidade Federal de Santa Catarina, 2015.

LEMOS, I. Narrativas de cotistas raciais sobre suas experiências na universidade. Revista Brasileira de Educação, v. 22, n. 71, e227161, 2017. https://doi.org/10.1590/ s1413-24782017227161

LEWGOY, B. Cotas Raciais na UNB: Lições de um equívoco. Horizontes Antropológicos, v. 11, n. 23, p. 218-221, 2005. https://doi.org/10.1590/S010471832005000100013 
MACHADO, E. Ação afirmativa, reserva de vagas e cotas na Universidade do Estado do Rio de Janeiro (2002-2012). Rio de Janeiro: Flacso, 2013.

MAGGIE, Y.; FRY, P. A reserva de vagas para negros nas universidades brasileiras. Estudos Avançados, São Paulo, v. 18, n. 50, p. 67-80, 2004. https://doi.org/10.1590/ S0103-40142004000100008

MATTOS, W.; MACEDO, K. A. S.; MATTOS, I. G. 10 anos de ações afirmativas na Uneb: desempenho comparativo entre cotistas e não cotistas de 2003 a 2009. Revista da ABPN, Florianópolis, v. 5, n. 11, p. 83-99, 2013.

MENDES JUNIOR, A. Uma análise da progressão dos alunos cotistas sobre a primeira ação afirmativa brasileira no ensino superior: o caso da Universidade do Estado do Rio de Janeiro. Ensaio: Avaliação e Políticas Públicas em Educação, Rio de Janeiro, v. 22, n. 82, p. 31-56, 2014. https://doi.org/10.1590/S0104-40362014000100003

MOEHLECKE, S. Ação afirmativa: história e debates no Brasil. Cadernos de Pesquisa, n. 117, p. 197-217, 2002. https://doi.org/10.1590/S0100-15742002000300011

MOREIRA SILVA, B. C. Desconstruindo mitos: meritocracia e a lei de cotas. Dissertação (Mestrado em Administração) - Universidade Federal de Viçosa, Viçosa, 2017.

SACRISTAN, G. Compreender y transformar la ensenanza. Madri: Morata, 1995.

SANTOS, M. C. O sistema de cotas da Universidade do Estado da Bahia: relato de uma experiência. In: PACHECO, J.; SILVA, M. (org.). O negro na universidade: $\mathrm{o}$ direito a inclusão. Brasília: Fundação Cultural Palmares, 2007. p. 99-124.

SENKEVICS, A. Contra o silêncio racial nos dados universitários. Educação e Pesquisa, v. 44, e182839, 2018. https://doi.org/10.1590/s16784634201844182839

SILVA, M. N.; PACHECO, J. Q. As cotas na Universidade Estadual de Londrina: balanço e perspectivas. In: SANTOS,J. (org.). O impacto das cotas nas universidades brasileiras (2004-2012). Salvador: CEAO, 2013. p. 67-104.

SOUZA, A. Avaliação da política de cotas na UEPG: desvelando o direito à igualdade e à diferença. Dissertação (Mestrado em Educação) - Universidade Estadual de Ponta Grossa, Ponta Grossa, 2012.

TAKAHASHI, R. As cotas baixaram a qualidade das universidades estaduais? $\mathbf{O}$ Globo, 2018.

VALENTE, R. R.; BERRY, B. J. L. Performance of Students Admitted through Affirmative Action in Brazil. Latin American Research Review, v. 52, n. 1, p. 18-34, 2017. http://doi.org/10.25222/larr.50

VELLOSO, J. Cotistas e não-cotistas: Rendimentos de alunos da Universidade de Brasília. Cadernos de Pesquisa, v. 39, n. 137, p. 621-644, 2009. https://doi.org/10.1590/ S0100-15742009000200014

WAINER, J.; MELGUIZO, T. Políticas de inclusão no ensino superior: avaliação do desempenho dos alunos baseado no Enade de 2012 a 2014. Educação e Pesquisa, v. 44, e162807, 2018. https://doi.org/10.1590/s1517-9702201612162807 


\section{SOBRE AUTORES}

Daniel Calbino Pinheiro é doutor em administração pela Universidade Federal de Minas Gerais (UFMG). Professor da Universidade Federal de São João Del-Rei (UFSJ).

E-mail:dcalbino@ufsj.edu.br

Rafael Diogo Pereira é doutor em administração pela Universidade Federal de Minas Gerais (UFMG). Professor da mesma instituição.

E-mail: rdp.ufmg@gmail.com

Wescley Silva Xavier é doutor em administração pela Universidade Federal de Minas Gerais (UFMG). Professor da Universidade Federal de Viçosa (UFV).

E-mail:wescleysxavier@yahoo.com.br

Conflitos de interesse: Os autores declaram que não possuem nenhum interesse comercial ou associativo que represente conflito de interesses em relação ao manuscrito.

Financiamento: $\mathrm{O}$ estudo não recebeu financiamento.

Contribuições dos autores: Análise Formal, Conceituação, Curadoria de Dados, Escrita Primeira Redação, Escrita - Revisão e Edição, Investigação, Metodologia: Pinheiro, D.C.; Pereira, R.D.; Xavier, W.S.

Recebido em 26 de abril de 2020

Aprovado em 18 de agosto de 2020 